\title{
Ensemble Evaluation of Hydrologically Enhanced Noah-LSM: Partitioning of the Water Balance in High-Resolution Simulations over the Little Washita River Experimental Watershed
}

\author{
ENRIQUe Rosero,* Lindsey E. GULDEN,* AND ZONG-LIANG YANG \\ Department of Geological Sciences, Jackson School of Geosciences, The University of Texas at Austin, Austin, Texas
}

Luis G. DE GONCALVES

NASA Goddard Space Flight Center, Hydrological Sciences Branch, Greenbelt, and Maryland Earth System Science Interdisciplinary Center, University of Maryland, College Park, College Park, Maryland

\section{GUO-Yue NiU}

Biosphere2 Earthscience, The University of Arizona, Tucson, Arizona

\author{
YASIR H. KAHEIL
}

International Research Institute for Climate and Society, Columbia University, Palisades, New York

(Manuscript received 23 October 2009, in final form 6 August 2010)

\begin{abstract}
The ability of two versions of the Noah land surface model (LSM) to simulate the water cycle of the Little Washita River experimental watershed is evaluated. One version that uses the standard hydrological parameterizations of Noah 2.7 (STD) is compared another version that replaces STD's subsurface hydrology with a simple aquifer model and topography-related surface and subsurface runoff parameterizations (GW). Simulations on a distributed grid at fine resolution are compared to the long-term distribution of observed dailymean runoff, the spatial statistics of observed soil moisture, and locally observed latent heat flux. The evaluation targets the typical behavior of ensembles of models that use realistic, near-optimal sets of parameters important to runoff. STD and GW overestimate the ratio of runoff to evapotranspiration. In the subset of STD and GW runs that best reproduce the timing and the volume of streamflow, the surface-to-subsurface runoff ratio is overestimated and simulated streamflow is much flashier than observations. Both models' soil columns wet and dry too quickly, implying that there are structural shortcomings in the formulation of STD that cannot be overcome by adding GW's increased complexity to the model. In its current formulation, GW extremely underestimates baseflow's contribution to total runoff and requires a shallow water table to function realistically. In the catchment (depth to water table $>10 \mathrm{~m}$ ), GW functions as a simple bucket model. Because model parameters are likely scale and site dependent, the need for even "physically based" models to be extensively calibrated for all domains on which they are applied is underscored.
\end{abstract}

\section{Introduction}

Among the components of the water balance, runoff has arguably the greatest importance for society. The

* Current affiliation: ExxonMobil Upstream Research Company, Houston, Texas.

Corresponding author address: Zong-Liang Yang, 1 University Station C1100, The University of Texas at Austin, Austin, TX 78712-0254. E-mail: liang@jsg.utexas.edu
Intergovernmental Panel on Climate Change (IPCC) identified the vulnerability of freshwater resources to climate change and highlighted the need for increased capacity to model runoff processes at high-resolution (catchment scale) within the land surface models (LSMs) that are linked to climate models (Bates et al. 2008). Such improvements, combined with more extensive, highresolution runoff datasets, are necessary to better assess the feedbacks affecting freshwater resources. Runoff, together with soil moisture, is in general poorly represented in LSMs (Viterbo 2002; Nijseen and Bastidas 
2005; Overgaard et al. 2006). Major uncertainty remains in LSMs' simulation of the surface water balance. Some of this uncertainty is governed by the parameterization of processes that drive runoff and the differences in the storage characteristics of LSMs (Wetzel et al. 1996; Pitman 2003). The strong interaction between the water and energy balances means that systematic errors in the allocation of moisture to reservoirs and runoff propagate to the partitioning of turbulent heat fluxes (Chen et al. 1997; Koster and Milly 1997; Liang et al. 1998; Wood et al. 1998; Dirmeyer 2006), which affects the simulation of weather and climate (Pitman et al. 1999; Li et al. 2007).

The complexity of the subsurface hydrology parameterizations in LSMs is relatively low when compared to the complexity of their parameterizations of aboveground processes (Stöckli et al. 2008). While most LSMs describe the canopy and root zone in great detail, the interactions between groundwater, the root zone, and surface water are usually neglected (Overgaard et al. 2006). Because of the lack of observations of water movement in the vadose zone, diverse representations of infiltration, drainage, and interflow processes in LSMs stem mainly from their unconstrained development, which focused primarily on regional fluxes to the atmosphere (Wetzel et al. 1996). Many LSMs, like the Noah LSM (Ek et al. 2003), neglect topographic effects, assume spatially continuous soil moisture values, parameterize surface runoff with a simple infiltration-excess scheme, and treat baseflow as a linear function of bottom soil-layer drainage (Schaake et al. 1996). More complex in its subsurface hydrology parameterizations than most LSMs, the multilevel reservoir Variable Infiltration Capacity (VIC) (Wood et al. 1992) family of models and its descendants (e.g., Liang et al. 1996) use a spatial probability distribution to represent subgrid heterogeneity in soil moisture and treat baseflow as a nonlinear recession curve. Alternative LSM runoff schemes such as the Catchment model (Koster et al. 2000; Ducharne et al. 2000) have been used only in limited research applications (e.g., Reichle and Koster 2005). Lately, groundwater dynamics have been incorporated into LSMs (e.g., Gutowski et al. 2002; Liang et al. 2003; Yeh and Eltahir 2005; Maxwell and Miller 2005; Niu et al. 2007; Fan et al. 2007; Kollet and Maxwell 2008).

Major concerted efforts to evaluate the ability of multiple LSMs to simulate runoff at coarse scales in temperate regions indicate that 1 ) bucket models are insufficiently complex to capture runoff processes (Wood et al. 1998; Lohmann et al. 1998). 2) Especially in semiarid regions, most LSMs overestimate mean annual runoff [and hence underestimate evapotranspiration (ET)] and that the overestimation of runoff is especially pronounced during summer and in the drier portions of the basin (Wood et al. 1998; Lohmann et al. 1998). 3) Models whose runoff schemes were dominated by subsurface runoff (baseflow) most accurately simulated summer-season runoff (Lohmann et al. 1998). 4) Most LSMs can simulate monthly total river runoff relatively well, provided that the precipitation and other forcing input data are sufficiently accurate (Oki et al. 1999). Performance degrades significantly when evaluated at a daily time scale, although most LSMS are still able to slightly outperform the mean discharge (Boone et al. 2004). 5) Increasing model grid resolution tends to increase the volume of simulated runoff (Boone et al. 2004), which implies that there may be a need for the revision of modeling formulations as increasingly finely gridded models and/or at catchmentbased models are used. 6) Model efficiency in the subbasins was found to be lower than the model efficiency for the entire watershed. 7) LSMs appear to be sensitive to subgrid runoff parameterizations (Stöckli et al. 2007) and model parameters (Wood et al. 1998). 8) With appropriate automatic calibration of a large number of parameters and with the introduction of correction factors for the model forcing (precipitation and incoming radiation), LSMs can simulate runoff at $1 / 8^{\circ}$ with accuracy comparable to that of the conceptual hydrological models participating in the Model Parameter Estimation Experiment (MOPEX) (Nasonova et al. 2009).

The multimodel intercomparisons' use of only one or a few model realizations, however, has made it difficult to definitively attribute the sensitivity of runoff simulations to parameterization, to parameters, or to a combination of the two. The identification and evaluation of distributed hydrological models is complicated by the large number of model parameters and the lack of sufficiently powerful methods that can be used to perform a truly distributed assessment of model performance (e.g., Beven 1989, 2001, 2002; Konikow and Bredehoeft 1992; Refsgaard 1997; Refsgaard and Henriksen 2004). We attempt such a comparison here.

We evaluate the ability of two versions of the Noah LSM to simulate the water cycle at high spatial and temporal resolution without the use of forcing-correction factors. The runoff parameterization of the standard release 2.71 of the Noah LSM (STD) is compared against a version of the Noah LSM that has been augmented with a lumped, unconfined aquifer model (GW). GW represents the vertical flow of water between the soil column and an aquifer according to a parameterization of Darcy's Law. In an effort to capture the subgrid heterogeneity in land surface properties that controls runoff generation, a TOPMODEL-based parameterization (Niu et al. 2005, 2007) replaces in GW the surface and subsurface runoff parameterizations of STD. We hypothesize that because of GW's increased complexity and conceptual realism when 
compared to STD, and because of GW's good performance in reproducing near-surface fluxes and states at single points in semihumid regions of transition zones (Rosero et al. 2009, 2010), GW will outperform STD when simulating runoff.

We address the following broad questions: Can a medium-complexity LSM (i.e., Noah STD) simulate runoff at a fine spatial and temporal resolution in a zone of transition between humid and arid climates? Does the addition of a more complex, physically realistic parameterization of groundwater dynamics and topographybased runoff improve the model's capacity to simulate runoff? Note that we do not expect the LSMs to be able to provide highly accurate mean daily discharge predictions; rather, we evaluate them based on their capacity to reproduce the essential components and character of runoff generation and of the water balance. We use an extensive evaluation approach that incorporates the models' typical behavior (i.e., their "signatures") of ensembles that use realistic, near-optimal sets of parameters (Rosero et al. 2009, 2010). We focus extensively on a set of Monte Carlo-derived behavioral runs that best reproduce the timing and the volume of streamflow.

Our chosen modeling domain is the Little Washita River Experimental Watershed (LWREW; Allen and Naney 1991) (Fig. 1). Noting the community's call for increased spatial and temporal scales when predicting runoff, we run both versions of Noah LSM on a $4-\mathrm{km}$ grid and evaluate daily river discharge. We further assess the models' abilities to simultaneously simulate runoff, soil moisture, and evapotranspiration. This analysis is at a finer temporal and spatial scale than has been done previously for LSMs.

This is a preliminary study aimed toward improved runoff simulation within LSMs. Because of the small scale of the basin we assume routing is not necessary to predict daily total streamflow volumes (Fig. 2). We further assume that the meteorological input forcing data are accurate enough (i.e., no correction is required, Fig. 3).

Section 2 introduces the models, evaluation datasets, and Monte Carlo-based methods. Section 3 presents the results of the intercomparison. Discussion of our conclusions is offered in section 4 .

\section{Data, models, and methods}

We used two versions of the Noah LSM (Ek et al. 2003; Mitchell et al. 2004) to produce ensembles of LSM realizations of near-surface states and fluxes over the Little Washita basin in Oklahoma from 1 January 1997 to 31 December 2007. The first five years of model output are treated as spinup. We evaluate simulations of the period 1 January 2002 to 31 December 2007.

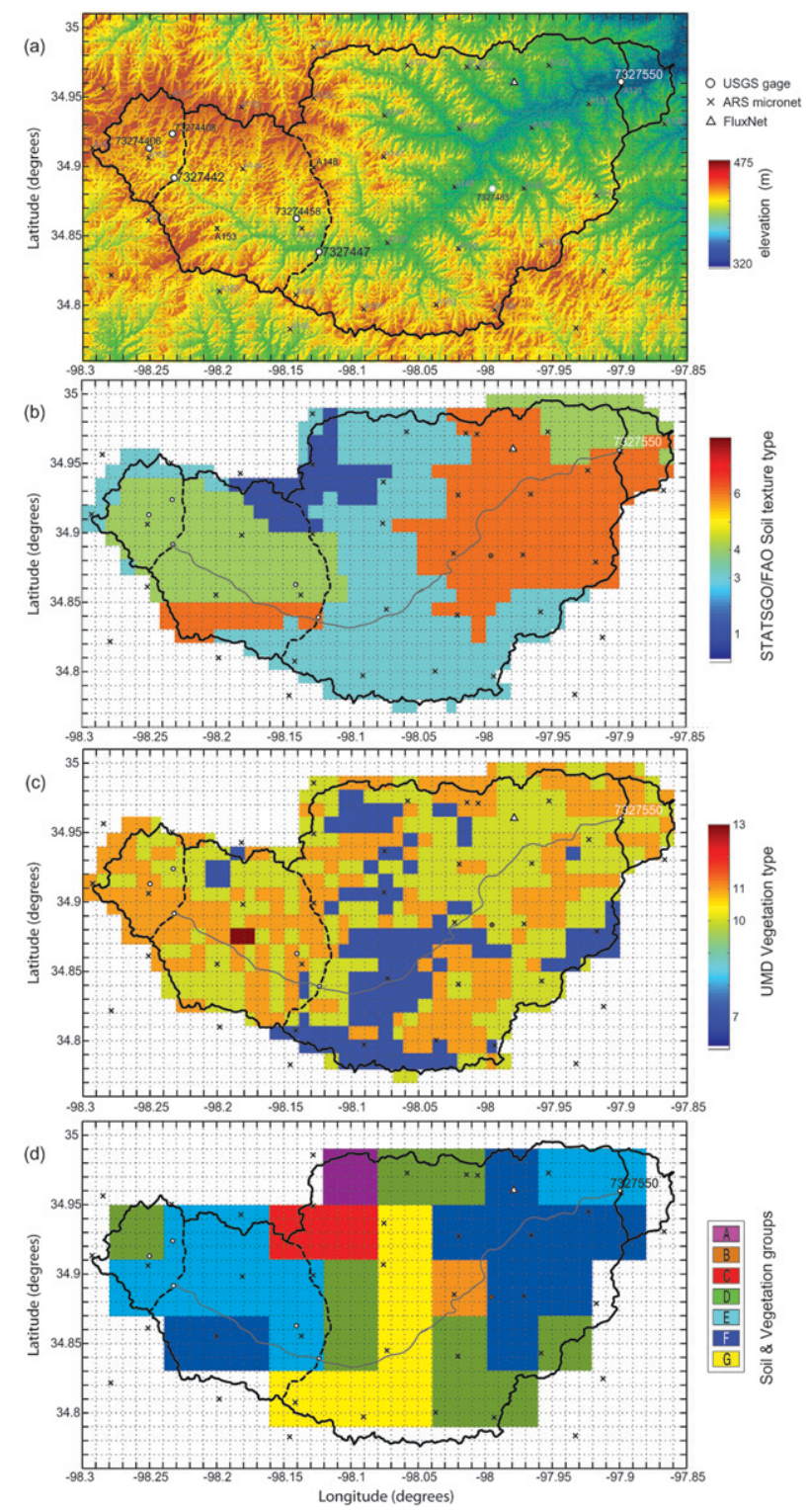

FIG. 1. LWREW modeling domain. (a) Hydrography and locations of the USGS streamflow gauges, ARS soil moisture observation sites, and the FLUXNET tower. (b) 1-km FAO/STATSGO soil texture data. (c) 1-km UMD vegetation type data. (d) Groups A-G of cells with the same vegetation and soil types on the 4-km modeling domain used in all model realizations described here. Note the delineation of 3 subbasins: upstream (7327442), midcatchment (7327447), and downstream at the outlet (7327550). See Table 1 for soil and vegetation classification.

\section{a. The Little Washita River Experimental Watershed}

The LWREW (Fig. 1), a tributary of the Washita River, is just south of $35^{\circ} \mathrm{N}$ and is centered on $-98^{\circ} \mathrm{E}$. Grass, crops, and wooded grassland cover the $611-\mathrm{km}^{2}$ basin, which contains soil types ranging from fine sand to silty loam. The climate is temperate and continental: 


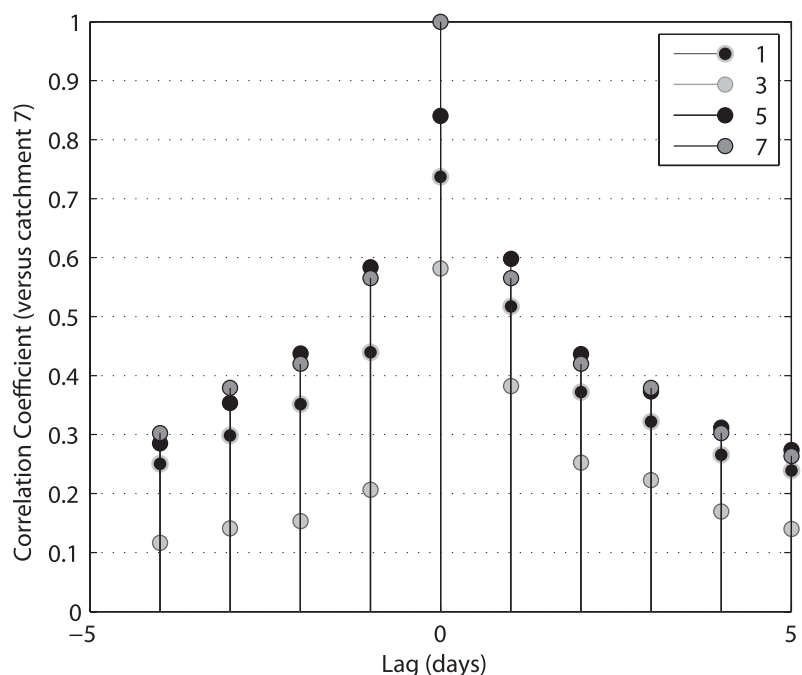

FIG. 2. Lag-correlation coefficients between streamflow at the outlet gauge (07327550) and gauges upstream. The maximum correlation of the time series correlation has a time lag of 0 days.

average annual rainfall is $760 \mathrm{~mm}$. Most precipitation is received in the spring and fall. Summers are long, hot, and dry; winters are short, temperate, and dry. Mean annual temperature is $16^{\circ} \mathrm{C}$. Daily-mean maximum (minimum) temperature in July is $35^{\circ} \mathrm{C}\left(21^{\circ} \mathrm{C}\right)$, and daily-mean maximum (minimum) temperature in January is $10^{\circ} \mathrm{C}$ $\left(-4^{\circ} \mathrm{C}\right)$. The influence of snow processes and frozen soil hydrology is negligible. The watershed is well drained, with gently rolling hills dominating the landscape. Maximum topographic relief is about $180 \mathrm{~m}$. The LWREW is slow draining: baseflow is a major component of overall runoff, which makes the basin an ideal location in which to test the parameterizations of GW. Additional description of the watershed can be found in Allen and Naney (1991).

\section{b. The Noah LSM}

Noah is a medium-complexity LSM that takes meteorological forcing as input and uses physically based equations to simulate near-surface states and surface-toatmosphere fluxes. Noah is used operationally by the National Centers for Environmental Prediction models and it is the land component of the Weather Research Forecasting model. Noah uses mass conservation and a diffusive form of the Richards equation to represent vertical water flow through its four-layer soil column (with lower boundaries at 0.1, 0.4, 1.0, and $2.0 \mathrm{~m}$ ). The dependency of hydraulic conductivity and soil matric potential on soil moisture is parameterized according to Clapp and Hornberger (1978).

The two versions of Noah that we used are hydrologically distinct: 1) in STD, the standard hydrological

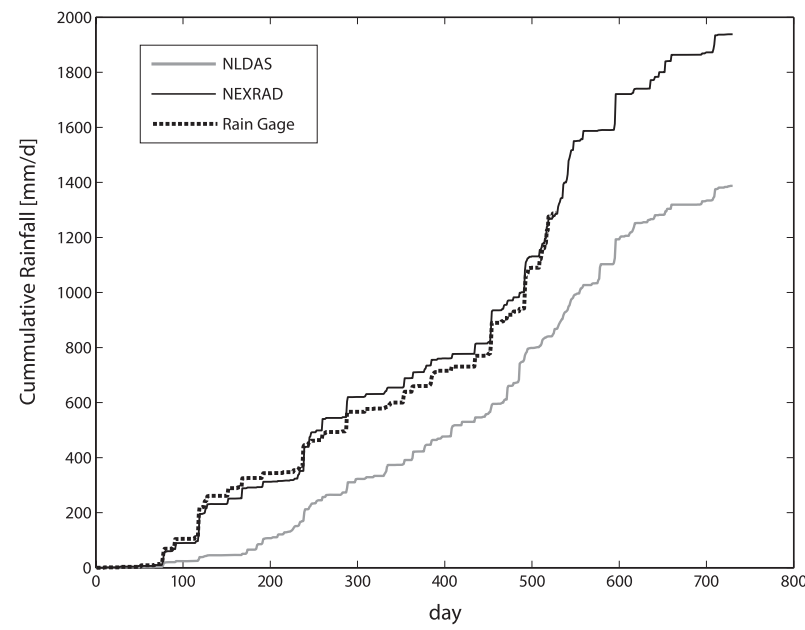

FIG. 3. NEXRAD precipitation at outlet grid cell compared to NLDAS and gauge A121 for 2006-07.

parameterizations of Noah release 2.71 are used; 2) in $\mathrm{GW}$, a simple aquifer model is coupled to the model's soil columns and the surface and subsurface runoff parameterizations of STD are replaced by the TOPMODELbased parameterizations of Niu et al. $(2005,2007)$.

Because the maximum time-lag correlation of daily streamflow between gauges upstream of the outlet is under 1 day, no routing scheme was used (Fig. 2), and the hourly runoff was simply aggregated downstream daily.

\section{1) THE STANDARD VERSION OF THE NOAH LSM (STD)}

STD uses an infiltration-excess parameterization to represent surface runoff and a gravitational drainage parameterization to represent subsurface runoff (Schaake et al. 1996). Surface runoff $\left(Q_{s}\right)$ is

$$
Q_{s}=P_{d}-\mathrm{Inf}_{\max },
$$

where $P_{d}$ is the rate at which water reaches the soil surface and $\mathrm{Inf}_{\max }$ is the maximum rate of infiltration into the soil. Here Inf $_{\max }$ is calculated as function of the hydraulic conductivity of the first soil layer, according to the subgrid parameterization of the water balance deficit as

$$
\mathrm{Inf}_{\max }=P_{d} \frac{D_{x}\left[1-\exp \left(-\mathrm{kdt} \times \delta_{t}\right)\right]}{P_{d}+D_{x}\left[1-\exp \left(-\mathrm{kdt} \times \delta_{t}\right)\right]},
$$

where $D_{x}$ is the soil moisture $(\theta)$ deficit term integrated across soil layers $\left(\Delta z_{i}\right)$ on time interval $\delta_{t}$ :

$$
D_{x}=\sum_{i=1}^{4} \Delta z_{i}\left(\theta_{\text {sat }}-\theta_{i}\right)
$$

and the variable kdt is calculated as a function of the parameter $\mathrm{kdt}_{\text {ref }}$ and the ratio of the saturated hydraulic conductivity $\left(K_{\text {sat }}\right)$ and its reference value $\left(K_{\text {ref }}\right)$ : 


$$
\mathrm{kdt}=\mathrm{kdt}_{\mathrm{ref}} \frac{K_{\mathrm{sat}}}{K_{\text {ref }}} .
$$

Subsurface runoff $\left(Q_{s b}\right)$ is

$$
Q_{s b}=\operatorname{Slope} K_{\text {nsoil }},
$$

where Slope is a scaling factor between 0 and 1 and $K_{\text {nsoil }}$ is the hydraulic conductivity of the bottom layer.

\section{2) The NoAh LSM AugMented WITH}

\section{A GROUNDWATER PARAMETERIZATION}

GW parameterizes both $Q_{s}$ and $Q_{s b}$ as a function of depth to water table $\left(z_{\mathrm{wt}}\right)$. In GW,

$$
Q_{s b}=\left(R_{s b_{\max }}\right) e^{-(f)\left(z_{\mathrm{wt}}\right)},
$$

where $R_{s b}$ is the maximum rate of subsurface runoff and $f$ is the $e$-folding depth of saturated hydraulic conductivity, which, following Silvapalan et al. (1987), is assumed to exponentially decay with depth. GW uses a similar parameterization for $Q_{s}$ :

$$
Q_{s}=\left(p_{d}\right)\left(f_{\text {sat }_{\text {max }}}\right) e^{-0.5(f)\left(z_{\mathrm{wt}}\right)}
$$

where $P_{d}$ is the rate of precipitation reaching the ground and $f_{\text {sat }_{\max }}$ is the maximum fraction of ground area that can be saturated.

\section{c. Meteorological forcing inputs and initialization}

We used hourly, 4-km Next Generation Weather Radar (NEXRAD) stage IV as precipitation input for all model runs after 1 January 2002. For all other meteorological forcing (longwave radiation, shortwave radiation, atmospheric pressure, wind speed, air temperature, and specific humidity), hourly North American Land Data Assimilation (NLDAS) meteorological forcing (Cosgrove et al. 2003) was used. The NLDAS forcing data were bilinearly interpolated from their native $12-\mathrm{km}$ resolution to the 4-km grid used to represent the LWREW (Fig. 1). We chose to use the NEXRAD precipitation in place of the NLDAS precipitation because the timing of rainfall, the volume of precipitation in individual events, and the cumulative volume of precipitation specified by the NEXRAD data were more consistent with the characteristics of 24 single-point observations obtained by the U.S. Department of Agriculture (USDA) Agricultural Resource Service (ARS) (Fig. 3).

Each model realization was spun up between 1 January 1997 and 31 December 2001. All runs were initialized with snow-free ground, a dry canopy, and at the approximate multiannual-mean temperature. Soil moisture was initialized as $50 \%$ of the realization's specified porosity. We used the equilibrium-water-table assumption of Niu et al. (2007) to initialize the water table for the Noah-GW realizations.

\section{d. Parameter values}

We used 1-km University of Maryland (UMD) vegetation data (Hansen et al. 2000) and 1-km Food and Agriculture Organization of the United Nations/U.S. General Soil Map (FAO/STATSGO2) soil texture classifications (Soil Survey Staff 2009), both of which were aggregated (using the most predominant type) to the 4-km grid shown in Fig. 1, to classify the basin according to seven unique soil-vegetation groups. Because it is unlikely that parameters vary solely as a function of soil type alone or of vegetation type alone (Rosero et al. 2010), and to reduce the total number of parameters studied, we described the domain as a mosaic of soil-vegetation classes (Table 1; Fig. 1d). For simplicity and to ease computational burden, when identifying the soil-vegetation groups, we treated crop and grass as the same vegetation class.

We vary a total of 61 parameters for STD and 64 for GW for the distributed run. In a given grid cell, for each of the STD realizations, 9 parameters deemed important to the simulation of soil hydrology ( 8 soil and vegetation parameters and 1 basin-topography-related parameter) were randomly sampled from uniform distributions (see Table 2); for the GW realizations, 10 parameters (7 soil and vegetation parameters and 3 basin parameters) were allowed to vary. For each model run, a unique parameter set was assigned to each soil-vegetation class (Fig. 1d) and to each of the five subbasins in the watershed. That is, the parameters of each soil-vegetation class and each basin varied independently, and all the cells within a class (or basin) had the same soil-vegetation (or basin) parameters. Ranges in Table 2 were taken from the literature (e.g., Chen et al. 1996; Schaake et al. 1996; Bastidas et al. 2006; Hogue et al. 2006). Parameters that were held constant between realizations were set to the default value used by Niu et al. (2010, manuscript submitted to J. Geophys. Res.) for that vegetation or soil type or, in the case of GW parameters, to the default values set by Niu et al. (2007).

\section{e. Evaluation data}

We evaluated model performance by comparing simulated daily-mean discharge rate to observed data collected by the U.S. Geological Survey (USGS). We obtained data for the five gauging stations (73274406, 73274458, 7327442, 7327447, and 7327550) within the LWREW for which data were available for the model-evaluation period online at http://waterdata.usgs.gov/nwis.

We compared hourly simulated latent heat flux for 1 January 1998-31 December 1998 to the mean hourly observed latent heat flux (Meyers 2001) obtained at the 
TABLE 1. Soil-vegetation properties.

\begin{tabular}{|c|c|c|c|c|c|c|}
\hline $\begin{array}{l}\text { Soil-vegetation } \\
\text { group }\end{array}$ & Vegetation type & $\begin{array}{l}\text { Vegetation } \\
\text { index* }\end{array}$ & Soil type & $\begin{array}{c}\text { Soil } \\
\text { index* }\end{array}$ & $\begin{array}{c}\text { Number of } \\
\text { 4-km grid cells }\end{array}$ & $\begin{array}{c}\text { Area } \mathrm{km}^{2} \\
\text { (fraction \%) }\end{array}$ \\
\hline A & Wooded grassland & 7 & Sand & 1 & 1 & $16(2.63)$ \\
\hline $\mathrm{B}$ & Wooded grassland & 7 & Loam & 6 & 1 & $16(2.63)$ \\
\hline $\mathrm{C}$ & Grassland/cropland & 10,11 & Sand & 1 & 2 & $32(5.26)$ \\
\hline $\mathrm{D}$ & Grassland/cropland & 10,11 & Sandy loam & 3 & 9 & $144(23.68)$ \\
\hline $\mathrm{E}$ & Grassland/cropland & 10,11 & Silty loam & 4 & 9 & $144(23.68)$ \\
\hline $\mathrm{F}$ & Grassland/cropland & 10,11 & Loam & 6 & 10 & $160(26.31)$ \\
\hline $\mathrm{G}$ & Wooded grassland & 7 & Sandy loam & 3 & 6 & $96(15.78)$ \\
\hline
\end{tabular}

* See Fig. 1.

flux network (FLUXNET) site at Little Washita $\left(34.9604^{\circ} \mathrm{N}\right.$, $-97.9789^{\circ} \mathrm{E}$ ). (Data were accessed online at http://public. ornl.gov/ameriflux/Site_Info/siteInfo.cfm?KEYID=us. little_washita.01.) No latent heat flux observations within the LWREW were available for any other period of time.

Daily volumetric soil moisture observations at $5 \mathrm{~cm}$ and $25 \mathrm{~cm}$ for the period 1 January 2005-31 December 2007 for 24 sites within the LWREW were obtained from the USDA's ARS Micronet Web site (http://ars. mesonet.org/). Time series for selected sites (A148 and A153) and statistics of soil moisture for all the sites are compared.

\section{f. Monte Carlo-based evaluation methods}

\section{1) LATIN HYPERCUBE SAMPLING AND BEHAVIORAL MODEL REALIZATIONS}

Using Monte Carlo simulation, we obtained ensemble predictions of watershed responses using samples of parameter sets drawn from within feasible parameter ranges
(Table 2). We used uniform prior distributions independently defined for each parameter to sample 125000 model realizations for STD and 200000 for GW using a Latin hypercube sampling algorithm because it combines the strengths of stratified and random sampling to ensure that all regions of the parameter space are represented in the sample (McKay et al. 1979). We classified models as behavioral or as nonbehavioral based on acceptable or unacceptable behavior (Hornberger and Spear 1981). The behavioral sample fulfilled a subjective threshold (Beven and Binley 1992) for this classification: conservation of mass [Eq. (11)]. It also minimized two measures of performance: heteroscedastic maximum likelihood estimation (HMLE) of daily flows (at stations 07327447 and 07327550), which accounts for timing, and the bias of monthly flows at the outlet gauge 07327550, which accounts for volume:

$$
\text { HMLE }=\sqrt[2]{\frac{1}{n} \sum_{i=1}^{n}\left(q_{\mathrm{sim}, i}^{t}-q_{\mathrm{obs}, i}^{t}\right)^{2}}
$$

TABLE 2. Bounds of distributions of parameters allowed to vary between realizations.

\begin{tabular}{|c|c|c|c|}
\hline Name & Description & Units & Feasible range \\
\hline \multicolumn{4}{|c|}{ Soil-vegetation parameters ${ }^{\mathrm{a}}$} \\
\hline$K_{\mathrm{ref}}^{\mathrm{b}}$ & (refdk) used with $\mathrm{kdt}_{\text {ref }}$ to compute runoff parameter $\mathrm{kdt}$ & - & $0.05-3.0$ \\
\hline $\mathrm{kdt}_{\text {ref }}^{\mathrm{b}}$ & (refkdt) surface runoff parameter & - & $0.1-10.0$ \\
\hline rcmin & Minimum stomatal resistance & $\mathrm{s} \mathrm{m}^{-1}$ & $30-200$ \\
\hline fxexp & Bare soil evaporation exponent & - & $0.1-2.0$ \\
\hline$b$ & Clapp-Hornberger $b$ exponent & - & $2-12$ \\
\hline$\theta_{\max }$ & $(\operatorname{smcmax})$ porosity & $\mathrm{m}^{3} \mathrm{~m}^{-3}$ & $0.2-0.5$ \\
\hline psisat & Saturated soil matric potential & $\mathrm{m} \mathrm{m}^{-1}$ & $0.03-0.76$ \\
\hline$K_{\text {sat }}$ & (satdk) saturated soil hydraulic conductivity & $\mathrm{m} \mathrm{s}^{-1}$ & $0.1-10$ \\
\hline rous ${ }^{c}$ & Aquifer-specific yield & $\mathrm{m}^{3} \mathrm{~m}^{-3}$ & $0.05-3.0$ \\
\hline \multicolumn{4}{|c|}{ Basin parameters ${ }^{\mathrm{d}}$} \\
\hline $\operatorname{rsbmax}^{c}$ & Maximum rate of subsurface runoff & $\mathrm{m} \mathrm{s}^{-1}$ & $1.0 \mathrm{E}^{-6}-1.0 \mathrm{E}^{-3}$ \\
\hline$f^{\mathrm{c}}$ & $e$-folding depth of saturated hydraulic conductivity & $\mathrm{m}^{-1}$ & $0.5-10$ \\
\hline fsatmx $x^{c}$ & Maximum saturated fraction & $\%$ & $0.1-90$ \\
\hline slope $^{b}$ & Slope of bottom soil layer & - & $0-1$ \\
\hline
\end{tabular}

a Assigned to all the cells within a soil-vegetation class (see Fig. 1d).

${ }^{b}$ Parameter is used by Noah-STD only.

${ }^{c}$ Parameter is used by Noah-GW only.

d Assigned to all the cells within a subbasin to better capture the topographic relief of the catchment. 

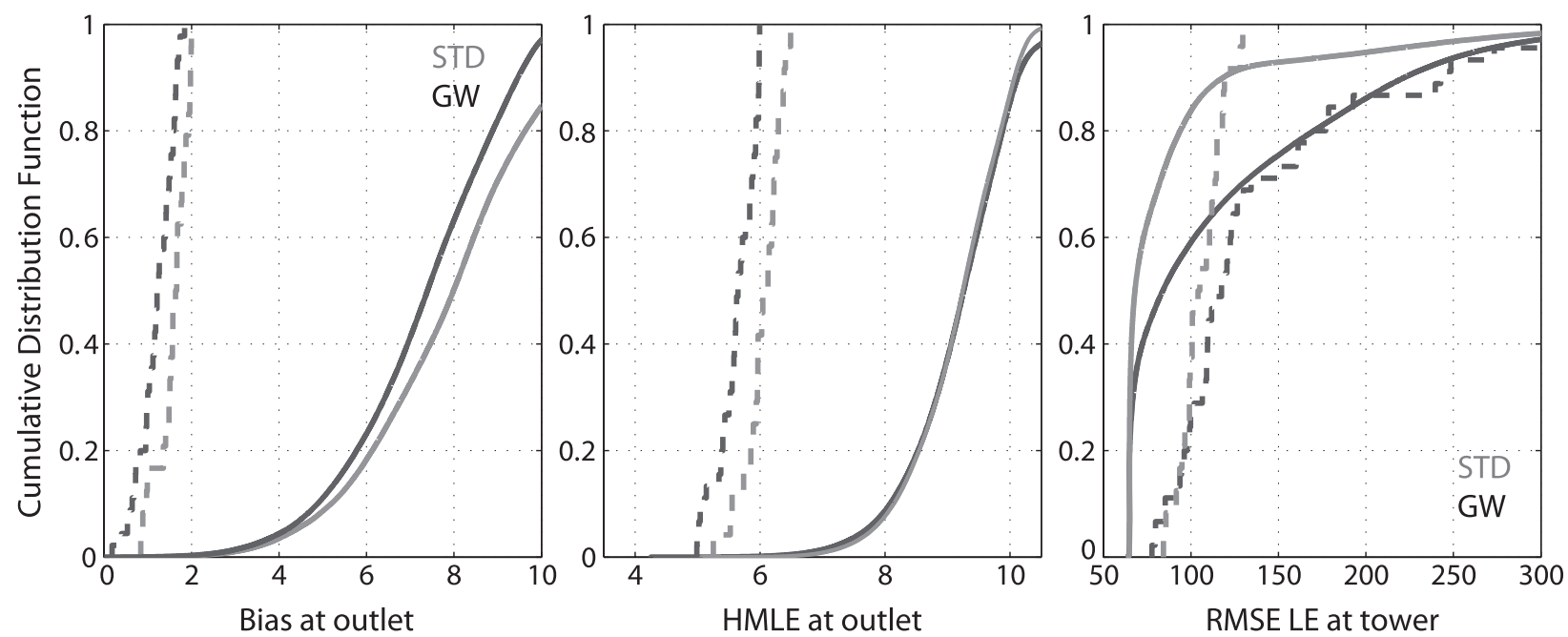

FIG. 4. Performance of all realizations of STD and GW. CDFs and histograms are shown for (a) the bias at the watershed outlet, (b) the HMLE at the watershed outlet, and (c) the RMSE of the 1998 latent heat flux. In all panels, CDFs with solid lines are those for all Monte Carlo realizations of STD (gray) and GW (black); dashed lines are the CDFs of the behavioral runs (for which both bias and HMLE were minimized).

$$
q_{i}^{t}=\frac{\left(Q_{i}-1\right)^{\lambda}}{\lambda}
$$

where $q_{i}^{t}$ is the transformed flow (Box and Cox 1964) with $\lambda=0.3$ (Sorooshian and Dracup 1980). Also,

$$
\begin{aligned}
\operatorname{Bias} & =\frac{1}{n} \sum_{i=1}^{n}\left(Q_{\mathrm{sim}, i}-Q_{\mathrm{obs}, i}\right), \\
\frac{E}{P} & \leq 1,
\end{aligned}
$$

where $E$ and $P$ are the multiannual-mean evaporation and precipitation, respectively.

The behavioral runs are those that are best able to reflect the timing and the volume of streamflow without violating the long-term water balance. We used Monte Carlo filtering (Ratto et al. 2007) (Bias $<2$, $\left.\operatorname{HMLE}_{(07327447)}<4, \operatorname{HMLE}_{(07327550)}<6, E / P<1\right)$ only as a screening tool after which further analysis of the behavioral ensemble was performed.

\section{2) Sobol' SENSITIVITY INDEXES}

We used the variance-based method of Sobol' (Sobol' $1993,2001)$ to efficiently identify the factors that contribute most to the variance of a model's response. The first-order sensitivity index $\left(S_{1, k}\right)$ represents a measure of the sensitivity of the performance of a model realization that is evaluated against observations to variations in parameter $x_{k}$. Here $S_{1, k}$ is defined as the ratio of the variance conditioned on the $k$ th factor to the total unconditional variance of the performance measure [e.g., Eqs. (8) and (10)]. For details see Saltelli (2002). We used the Sobol' semirandom sampling sequence, as implemented in SimLab (Saltelli et al. 2004), to evaluate 8320 and 11008 runs for STD and GW, respectively. The number of realizations allowed us to use a sample size larger than 128 for each parameter.

\section{3) ENSEMBLE-BASED PERFORMANCE SCORE}

The performance of the behavioral ensemble at every time step $i$ was quantified using the score of Gulden et al. (2008):

$$
\mathrm{s}_{i}=\frac{\mathrm{CDF}_{\mathrm{ens}, i}-\mathrm{CDF}_{\mathrm{obs}, i}}{1-C D F_{\overline{\mathrm{obs}}}},
$$

where $\mathrm{CDF}$ is the cumulative distribution function of the ensemble or the observed quantity. The score is lowest (i.e., best) when the ensemble brackets the observation, is highly skilled (observations centered on the ensemble mean), and has low spread.

\section{Results}

\section{a. Most frequent performance and behavioral model runs}

The typical performance of the 125 000-member STD ensemble and the 200 000-member GW ensemble suggest a wet bias in the total amount of simulated discharge and the inability of both models to adequately capture the timing of the daily streamflow in the LWREW (Fig. 4). Both STD and GW tend to overpredict the ratio of runoff to total precipitation (Fig. 5b); however, the bias of total watershed discharge simulated by GW tends to be slightly lower than that simulated by STD (solid lines in 

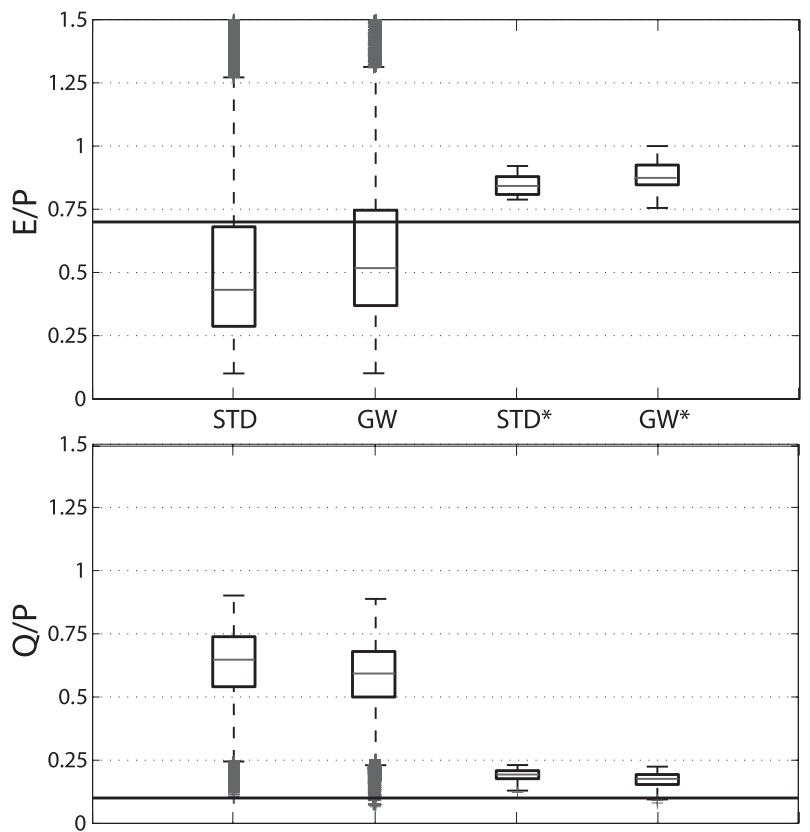

FIG. 5. Box plots showing the 2002-07 hydrologic response of the basin in terms of (a) evaporative $(E / P)$ and (b) runoff $(Q / P)$ ratios for are all Monte Carlo realizations and the behavioral subset of runs $(*)$, which minimized bias and HMLE. The box at shows interquartile range (i.e., the range between the first and the third quartiles) of the ratios and the length of the whiskers is 1.5 times the vertical scale of the boxes. Ratios outside of the whiskers are regarded as outliers and marked as crosses in the figure. For reference, the horizontal line in (a) stands for $E / P=0.7$ observed at the FLUXNET tower for 1997-98. The line in (b) stands for $Q / P=$ 0.1 observed at the outlet for 1997-2007.

Fig. 4a). The typical simulation of runoff by STD achieves an equally good HMLE as does that of GW (solid lines in Fig. 4b). GW tends to overestimate the evaporative flux; the RMSE of its simulated latent heat flux $(L E)$ is significantly greater than STD (Fig. 4c). Dotted lines in the panels of Figs. 4a,b show that calibration of model parameters leads to a significant reduction in the simulations' bias and HMLE; however, as reported in myriad other studies (e.g., Koster and Milly 1997) there exists a trade-off between a model achieving better runoff performance and accurate simulation of evapotranspiration. The top $0.05 \%$ of model runs (behavioral) constrained to better capture basic characteristics of the runoff does not yield improved simulations of latent heat flux. The tuning of model parameters significantly improves performance but is insufficient to overcome structural biases in model formulation.

\section{b. Partitioning of the water cycle}

The majority of simulations of STD and GW are unable to capture the fundamental features of the long-term hydrologic response of the basin (Fig. 5). We treat the 4-km NEXRAD stage IV precipitation data, used as meteorological input to the model cohorts, as observed precipitation and use them to compute evaporative $(E / P)$ and runoff $(Q / P)$ ratios. Noah's tendency to overestimate runoff volumes is shown in the positively (negatively) skewed $E / P(Q / P)$. The $Q / P$ ratio is overestimated by interquartile range of the STD and GW runs by a factor of 6 (Fig. 5b). Treating the evaporation observed at the AmeriFlux site to be approximately representative of the rates for the entire basin, we compute an estimated observed $E / P$ ratio (solid line in Fig. 5a). Seventy-five percent of the runs of both models underestimate the evaporative ratio. We presume that this estimated observed $E / P$ is itself likely an underestimate of the actual ET in the LWREW; therefore, the dry bias of the model-ensemble-simulated ET is likely even greater than it appears in Fig. 5. The subset of behavioral models (that achieve the lowest bias and best HMLE scores) do nearly conserve mass and are able to reasonably accurately simulate the gross characteristics of the LWREW water balance (STD* and GW* in Fig. 5).

\section{c. Ensemble-based evaluation of daily streamflow}

Having established that neither STD nor GW is skilled in simulating the large-scale features of the water balance, we sharpened our focus to the daily time scale as a means for understanding why the two version of Noah fail to capture essential features of the water cycle in the LWREW. We examined the best performing subset of models and examined in more detail the components of runoff simulation and the hydrologic cycle. Results presented in this section apply only to the behavioral (lowest bias and best HMLE) subset of runs for both STD and GW.

\section{1) HYDROGRAPHS AND RECESSION CURVES}

The streamflow hydrographs suggest that the models are limited in their ability to capture the timing of daily runoff and have less skill with respect to the magnitude, especially during dry spells. During wet periods, such as the spring and summer of 2007, both STD and GW simulate runoff that is overly flashy: the models are too responsive to small inputs of precipitation, they overestimate the rate of discharge after precipitation events, and the simulated recession of discharge is too fast (Fig. 6). After dry down, STD significantly outperforms GW; however, the difference in performance results from STD's larger baseflow (GW often has no baseflow at all; see further discussion below). During dry periods, such as the summer and early fall of 2005, STD again outperforms $\mathrm{GW}$, especially when baseflow is the primary source of water in the channel (Fig. 7). Both models overestimate postprecipitation increases in discharge and overestimate the speed at which channel flow recedes. Spurious peaks in 


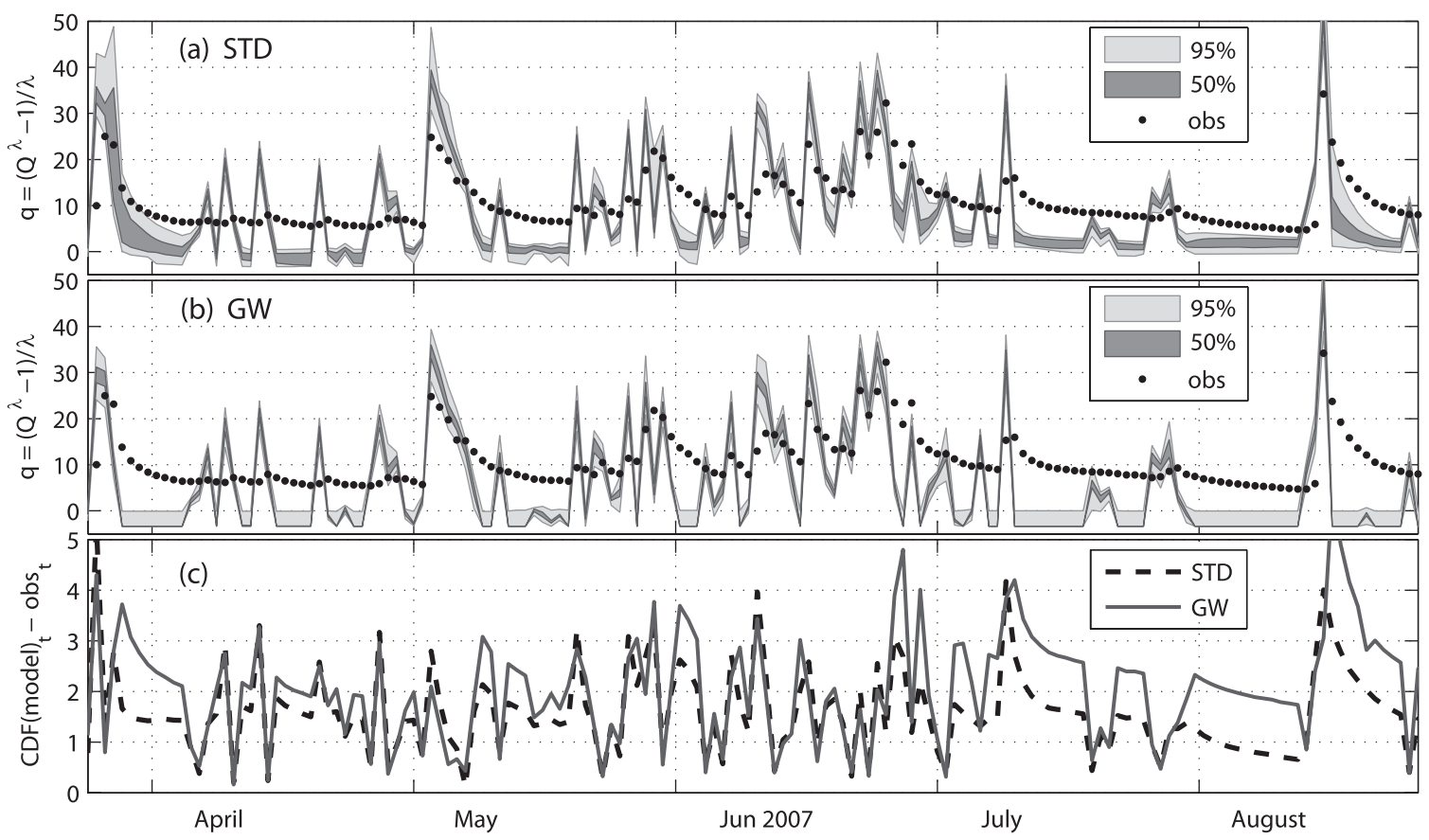

FIG. 6. Daily streamflow hydrograph simulated at the outlet (7327550) by the behavioral ensemble of (a) STD and (b) GW during a wet period in 2007. Transformed observed daily streamflow observations (cfs) are shown as black dots. Transformed runoff is used for improved visualization of both high and low flows. For both STD and GW, the 50 and $95 \%$ confidence intervals are shown. (c) Performance score (lower is better) of both STD and GW shows that both are too flashy (too high peaks and too persistent low flows), but STD consistently outperforms GW, especially during dry-down periods.

the hydrograph may indicate that the precipitation forcing data contain errors. The time-mean performance score of the Box-Cox transformed runoff (over the period 1 January 2002-31 December 2007) at the outlet is 1.42 for GW and 0.99 for STD (Table 3).

\section{2) Flow duration CuRve}

We use a flow exceedance probability curve (FEPC) (also known as the flow duration curve) (Vogel and Fennessey 1994) to summarize the models' ability to simulate the long-term distribution of flows of different magnitudes, which in turn is indicative of the different contributions made by surface and subsurface runoff to total streamflow (Farmer et al. 2003; Yilmaz et al. 2008; van Werkhoven et al. 2008) (Fig. 8). The FEPC represents the flow regime, and its steepness reflects the speed of watershed drainage, which is a result of the watershed functional behavior (Wagener et al. 2007). The gently sloping FEPC of the observed discharge indicates that groundwater or "slow" runoff is a significant contributor to the discharge (Smakhtin 2001) of the Little Washita River system in both its upstream (Fig. 8a) and downstream

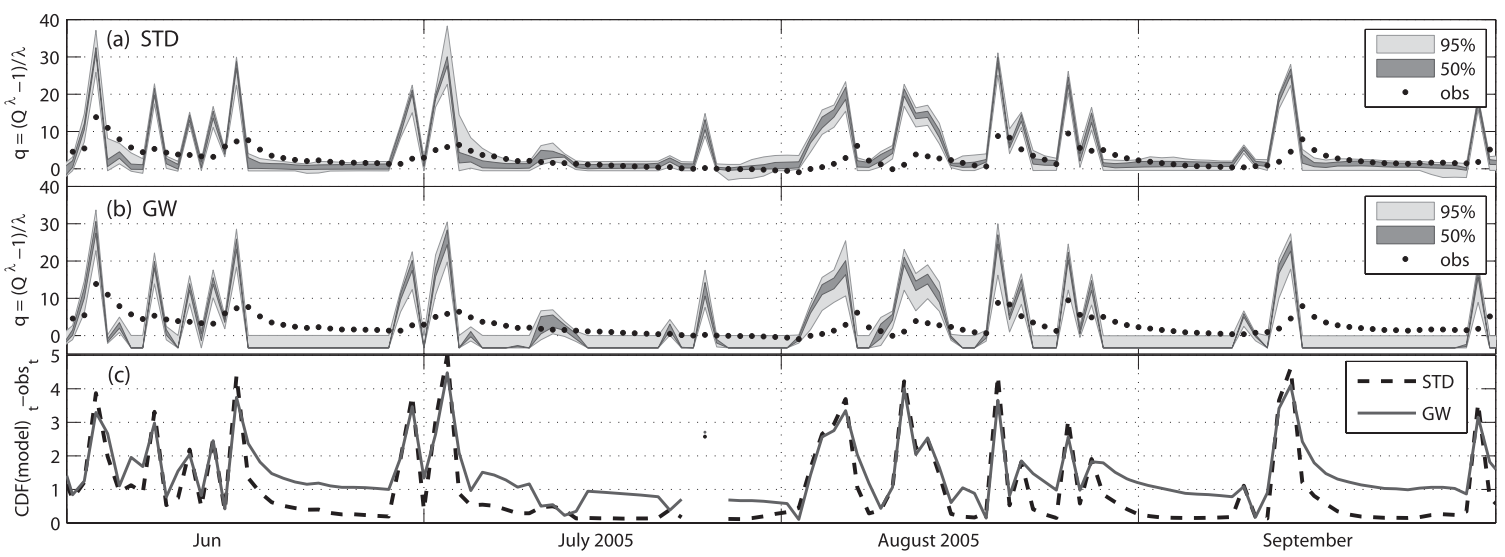

FIG. 7. As in Fig. 5, but for a dry period in 2005. 
TABLE 3. Performance score of the behavioral ensembles.

\begin{tabular}{|c|c|c|c|c|c|c|c|}
\hline \multirow[b]{2}{*}{ Station } & \multicolumn{3}{|c|}{ Runoff ( $\left.Q_{\text {total }}\right)$} & \multicolumn{2}{|c|}{$\mathrm{SMC}_{5 \mathrm{~cm}}$} & \multicolumn{2}{|c|}{$\mathrm{SMC}_{25 \mathrm{~cm}}$} \\
\hline & 7327442 & 7327447 & 7327550 & A148 & A153 & A148 & A153 \\
\hline STD & 1.66 & 1.42 & 0.99 & 0.58 & 0.57 & 0.61 & 0.67 \\
\hline GW & 1.6 & 1.69 & 1.42 & 0.62 & 0.63 & 0.6 & 0.71 \\
\hline
\end{tabular}

(Fig. 8b) reaches. Neither STD nor GW is able to capture this essential baseflow-dominated character of the LWREW streamflow (Fig. 8).

Both STD and GW simulate too-frequent high and extreme flows and too-infrequent intermediate and low flows. The models' short, steep FEPCs indicate that the models exhibit significant flow variability and limited flow persistence. At the midcatchment gauge (7327447), the entire GW behavioral ensemble and part of the STD cohort show that the model is much more flashy (i.e., with low water-storage capacity and overland-flowdominated runoff) than the actual Little Washita River (Fig. 8a). STD is more sensitive to the choice of parameters. At the downstream gauge (7327550), the behavioral ensemble of STD obtains more baseflow from the lowlands of the watershed (likely because of a change in soil-vegetation group type in the downstream reaches). Although the probability of intermediate and low flows in STD is lower than the observed, at the downstream gauge several realizations of STD do exhibit a distribution of flow volumes that somewhat resembles the slope of the observed FEPC, although STD's intermediate flows are dry biased with respect to observations (Fig. 8b). Even at the downstream gauge, GW simulations remain much flashier than observations. The FEPC of GW provides evidence that, in the LWREW, GW behaves as a simple bucket model that does not parameterize groundwater flow (Farmer et al. 2003; Wagener et al. 2007) (see section 4 for a discussion of this dichotomy).

\section{3) SPATIAL Distribution OF THE RUNOFF PARTITIONING}

Consistent with our foregoing observations, a spatial analysis of the ensemble mean of the cumulative surface $\left(Q_{s}\right)$ and subsurface $\left(Q_{s b}\right)$ flow shows that the total runoff $\left(Q_{\text {total }}\right)$ estimated by the two versions of Noah LSM is composed mostly of surface, overland, fast runoff (Fig. 9). The dominance of $Q_{s}$ is particularly pronounced for GW. That simulated $Q_{s} / Q_{\text {total }}$ is high is inconsistent with the observed FEPC, which shows a more slowly responding watershed.

\section{4) SEnsitive Parameters}

Analysis of the parameters most responsible for the model's behavior (Fig. 10) shows that for STD more

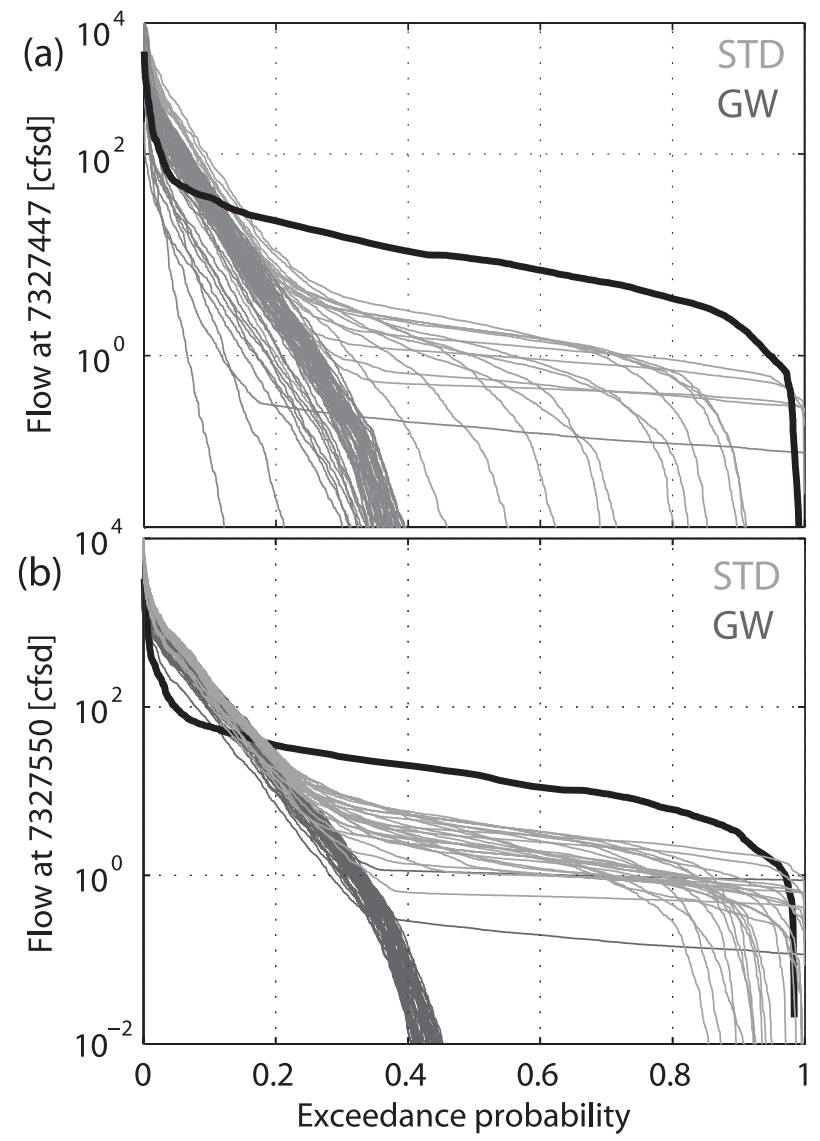

FIG. 8. FEPC of the $Q_{\text {total }}$ simulated by the behavioral ensembles of STD and GW for 2002-07 at (a) the intermediate gauge (7327447) and (b) the outlet (7237550). The FEPC of the observed streamflow (black) slopes gently, indicating that streamflow is dominated by baseflow. The FEPCs of the GW cohort (dark gray) resemble those of a bucket model; the FEPCs of STD (light gray) show a distribution more similar in shape to the observed but underpredicts medium and high probability events. For both, low probability, high-flow events are overpredicted.

than $70 \%$ of the variance is controlled by the ClappHornberger parameter $b$ of groups D-G, while for GW, less than $50 \%$ of the variance can be apportioned to $b$ of groups D and E. A quarter of GW's variance corresponds to the porosity (smcmax), saturated soil matric potential (psisat), and aquifer-specific yield (rous) of D-F. Despite that D-G correspond to the larger areas in the catchment, the fractions of the variance do not directly correspond to the area covered.

That the Clapp-Hornberger $b$ exponent is important for both STD and GW is not surprising: 1) Parameter $b$ controls the shape of the pedotransfer function from which the change of soil hydraulic conductivity with saturation is computed. 2) Parameter $b$ is also used to provide physical consistency between parameters: multiple internal model parameters (e.g., the wilting point, 

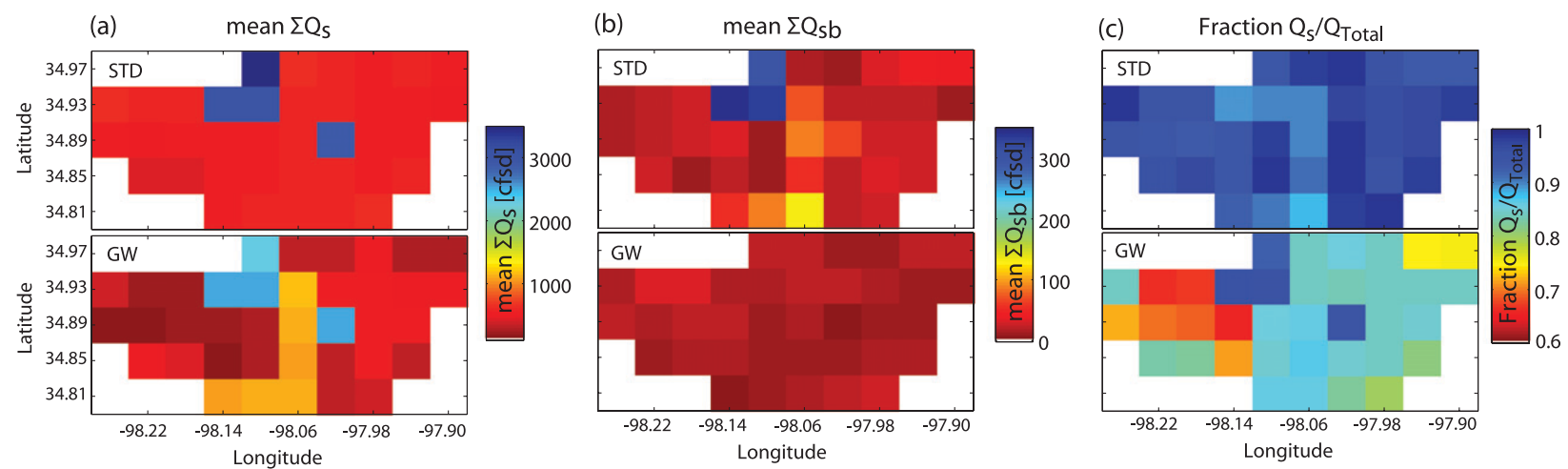

FIG. 9. Spatial distribution of ensemble-mean cumulative (a) surface runoff and (b) subsurface runoff. (bottom) GW has a higher ensemble-mean $Q_{s} / Q_{\text {total }}$ than (top) STD. In both STD and GW, surface runoff is controlled by soil-vegetation group distribution.

the saturated soil diffusivity, etc.) are computed using $b$ (Chen et al. 1996; Chen and Dudhia 2001).

Parameter $b$ plays a larger role in shaping the variance of runoff in STD than in GW (Fig. 10). In STD, $b$ is used to compute the maximum rate of infiltration (which controls surface runoff); it is also used to compute the hydraulic conductivity of the bottom layer of soil, of which $Q_{s b}$ is a linear function. In $\mathrm{GW}$, although $b$ still plays a role in determining the values of multiple soil hydraulic properties, it does not directly control surface runoff or subsurface runoff.

A comparison of Figs. 1 and 9 shows that in both models, but especially in GW, surface runoff is a function of soil-vegetation group and not of watershed. The only parameter indirectly used to compute surface runoff in GW that is also linked to land cover is the maximum canopy water content ( $\mathrm{cmcmax})$, which determines the amount of precipitation reaching the surface. Basin-linked parameters fsatmx and $f$ are also used to compute surface runoff, but Fig. 9 shows a clear dependence of surface runoff on soil-vegetation group. The variable groundwater table depth $\left(z_{\mathrm{wt}}\right)$ is the only remaining aspect of the GW computation of surface runoff that is indirectly linked to land-cover group, and it clearly is controlled by parameters of each soil-vegetation group (Fig. 11). GW's method of calculation of $z_{\mathrm{wt}}$ explains the contribution to model variance of smcmax, psisat, and rous (see Niu et al. 2005 for details on the calculation of $z_{\mathrm{wt}}$ ).

\section{d. Ensemble-based evaluation of daily soil moisture}

Point-based soil moisture measurements are difficult to compare with the spatially smoothed simulations of a model grid; however, statistical properties are often preserved across scales (Famiglietti et al. 2008). We compare the first, second, and third moments of observed and modeled soil moisture across the LWREW
(Fig. 12). Observed soil moisture observations reveal that the coefficient of variation $(\mathrm{CV})$ exhibits an exponentially decreasing pattern with increasing mean moisture content. In the upper soil layer $(5 \mathrm{~cm})$, the skewness of observed moisture generally decreases, from positive to negative values, with increasing mean soil moisture, with most observations centered around zero. In the root zone $(25 \mathrm{~cm})$, observed skewness shows approximately the same pattern, but with more scatter, and is on average slightly positive. Of the behavioral subset of model realizations, neither STD nor GW captures the essential character of the soil moisture statistics. Skewness is far too positive at both depths, and the coefficient of variation of simulated moisture increases with mean soil moisture. The addition of the groundwater module to STD does not fundamentally change the character of simulated soil moisture (Fig. 12). Observed soil moisture is more normally distributed than is modeled. In both models, simulated soil moisture is especially positively skewed for the driest cells: the model soil columns saturate quickly and then dry quickly, favoring lower-than-mean moisture. At both depths, observed soil moisture is more variable than modeled, and is most variable in drier cells. Near the surface, lower-mean grid cells have less moisture variation than their wetter counterparts; at depth, lower-mean grid cells exhibit more variation than their wetter counterparts. For both STD and GW, model output is consistent with expectations but not with reality. We (and likely the model developers) expect that the mean state of the soil moisture profile will monotonically wet with depth; yet observations show that in some cases this is not the case.

We use observations from two selected sites from within the basin (A148 and A153; see Fig. 1), each with distinct wetting profile and behavior, to evaluate model performance. The ensemble-mean, time-mean soil moisture profile of GW and STD slowly wet with depth at both sites, which is not consistent with observations 
STD
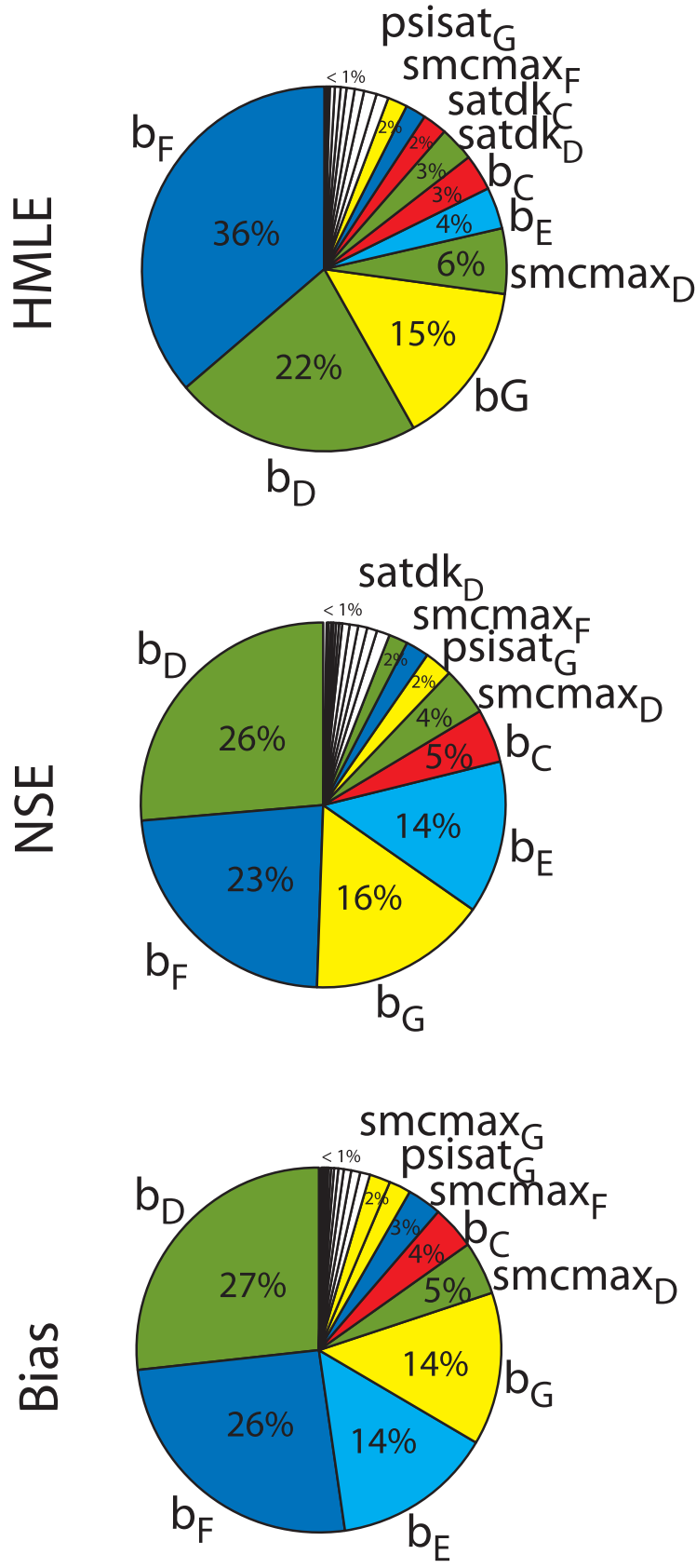

GW
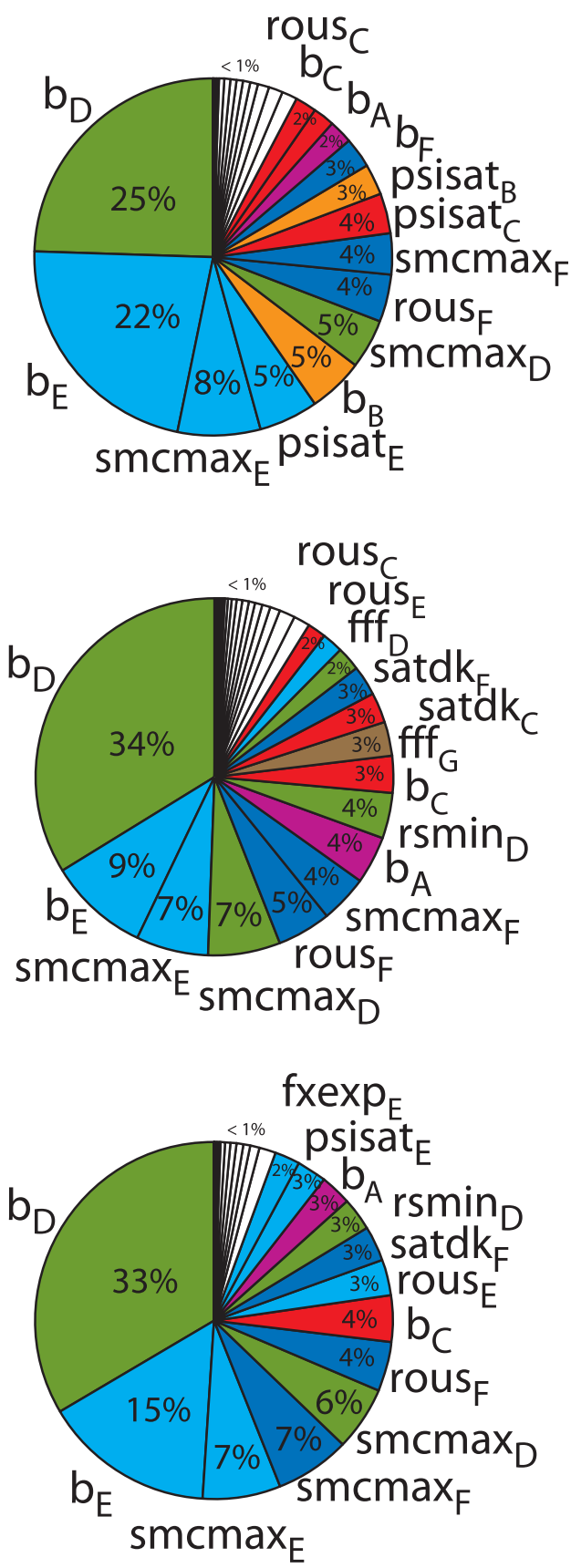

FIG. 10. Relative contribution of parameters to variance of the HMLE, Nash-Sutcliffe efficiency (NSE), and bias of simulated streamflow. Sensitivity analysis for (left) STD and (right) GW is shown. Parameters are color coded by soil-vegetation group type (see also group colors in Fig. 1d). Group types that cover larger areas (e.g., soil-vegetation groups D, E, F, and G) tend to have more importance in shaping variance.

(Fig. 13). Simulated gradual wetting with depth is consistent across the basin; only the uppermost layer of soil varies consistently between soil-vegetation groups (Fig. 14).
Time series of simulated soil moisture are plausibly realistic at both $5 \mathrm{~cm}$ and in the rooting zone, although both STD and GW simulate soils that exhibit a dry bias in the top layer when compared to observations (Figs. 15 


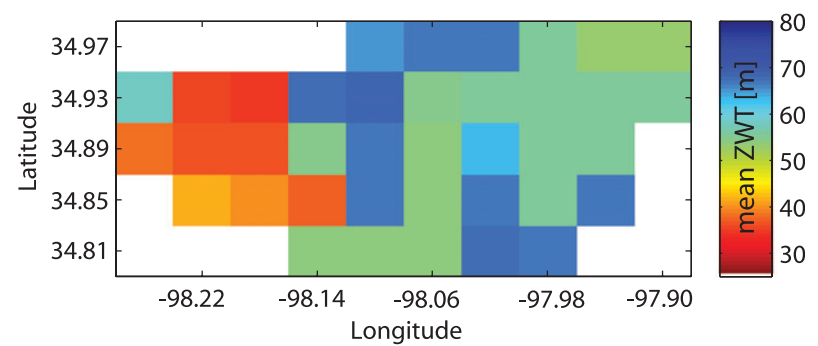

FIG. 11. Ensemble-mean depth to groundwater table $\left(z_{\mathrm{wt}}\right)$ of simulated by the behavioral ensemble of GW.

and 16). Although the simulations exhibit little differentiation between sites and between regions of the catchment, the models tend to perform better in the root zone of site A148 (Fig. 16). The amount of time that it takes for the soil to dry down is consistent with observations, although the magnitude of the change in modeled soil moisture is normally much greater than what is observed. It appears that the model may have a (dry) equilibrium state that it strongly prefers, possibly in spite of local forcing (Fig. 16). Performance scores for both models at the sites and depths are very similar (Table 3).

\section{e. Ensemble-based evaluation of daily ET}

In most parts of the basin, the time-averaged ensemblemean ET rates are much larger in GW than in STD; a qualitative examination of the spatial distribution of ET shows that ET rates are controlled by soil-vegetation group parameter choices, not by basin-related parameters. Examination of the performance of the behavioral ensemble when simulating the time variation of daily ET at a single grid cell (where the FLUXNET tower is located) shows that both GW and STD are too variable in their ET simulation and show that both models, but especially GW, overestimate ET at the given site (Fig. 17). This result is consistent with the overly robust evapotranspiration pathway observed for $\mathrm{GW}$ in previous studies (Rosero et al. 2009). We note that it is possible that the eddy-flux tower location from which the ET data were collected may not be representative of the ET flux averaged across the domain of the overlapping 4-km grid cell.
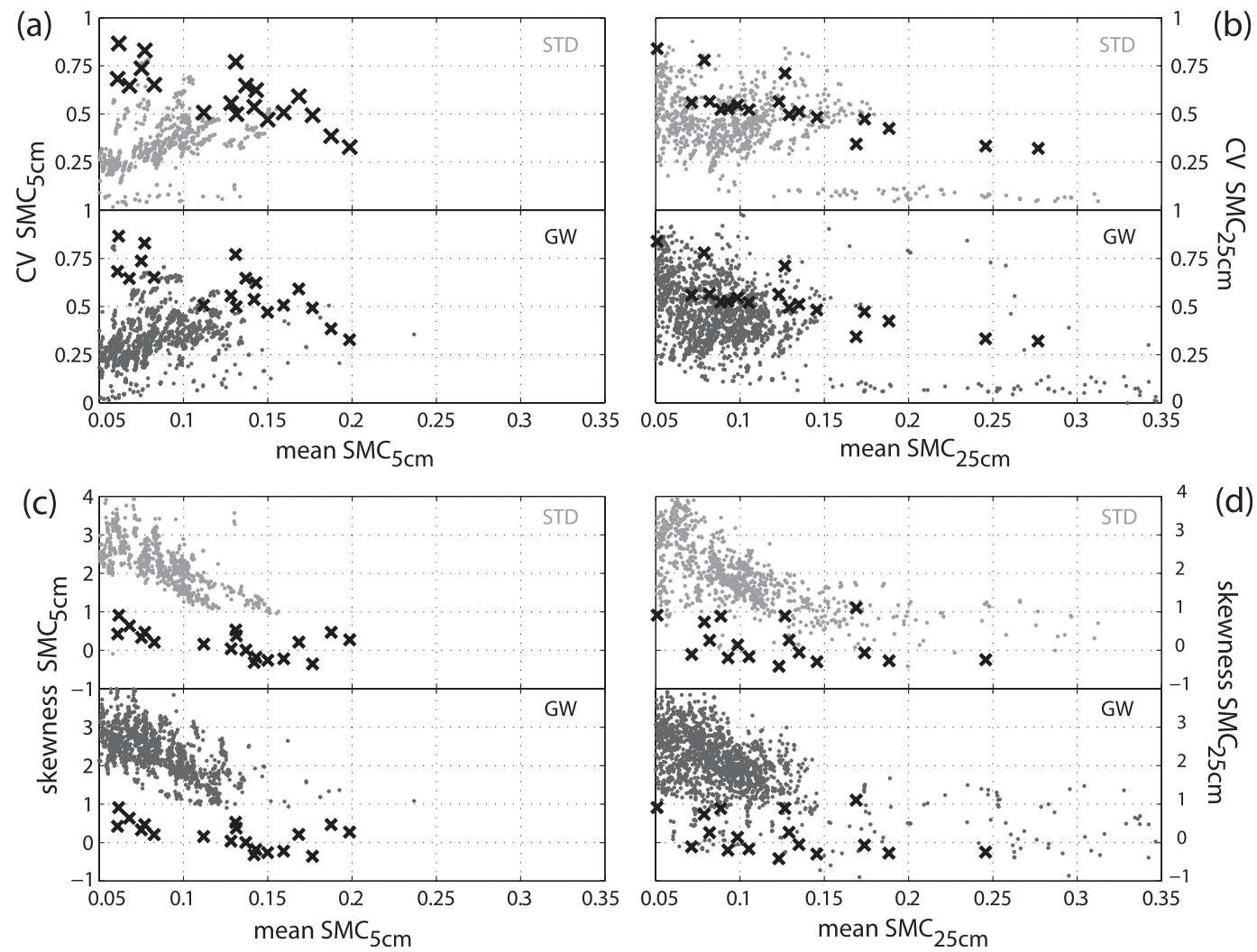

FIG. 12. Scatterplots of soil moisture statistics for observed and simulated soil moisture content (SMC). Mean SMC vs the CV of SMC are shown for (a) 5 and (b) $25 \mathrm{~cm}$. Mean SMC vs the skewness of SMC are shown for (c) 5 and (d) $25 \mathrm{~cm}$. The subsets of the simulated soil moisture statistics (STD: light gray dots; GW: dark gray dots) tend not to follow the same patterns as ARS observations (black). 


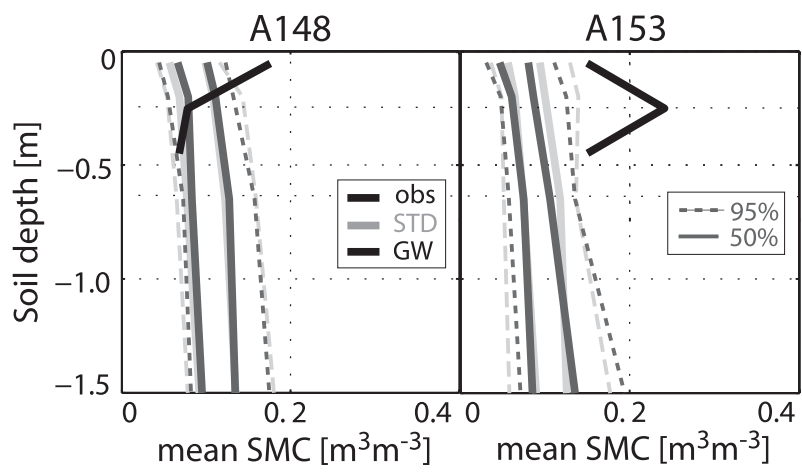

FIG. 13. Ensemble-mean SMC profile compared with 2006-07 observations at ARS sites A148 (north upper catchment) and A153 (south upper catchment) (Fig. 1a). Ensemble-mean SMC profiles are more consistent between behavioral models and between sites than they are with observations.

\section{Summary and discussion}

We conclude that, in their current formulations and on a 4-km grid, neither STD nor GW is able to capture the essential characteristics of runoff in the Little Washita River basin. A fundamental failure of the Noah STD soil parameterization is its inability to produce sustained baseflow for streams; the addition of the simple groundwater parameterization used here does not ameliorate this deficiency. In regions where the modeled water table is deep ( $>10 \mathrm{~m}$ below the surface), GW does not simulate sufficient baseflow and instead causes the model to function as a simple bucket model. Both models have too high a ratio of surface to subsurface runoff and consequently simulate streamflow that is far too flashy. In both models, the soil column wets too quickly and dries too quickly. We note that parameters for both models are likely scale and site dependent, and we underscore the need for even "physically based" models to be calibrated at all locations in which they are applied.

The failure of our implementations of STD and GW to realistically represent runoff in a small baseflowdominated watershed appears to result in large measure from the models' inability to adequately represent the soil hydrology and a steady subsurface runoff. Consequently, both models significantly overestimate the fraction of total runoff $\left(Q_{T}\right)$ that is rapid. Our results are consistent with the conclusions of Boone et al. (2004), who observed that, in general, higher ratios of surface runoff $\left(Q_{s}\right)$ to total runoff $\left(Q_{s} / Q_{T}>0.25\right)$ corresponded to less-realistic simulated discharge. Lower $Q_{s} / Q_{T}$ values were especially important for obtaining good performance at a daily time scale. Boone et al. (2004) also observed that schemes with little water-storage capacity in their soils tend to overestimate runoff; both STD and GW can be characterized as having low water-storage capacity in their soils: they both wet and dry too quickly in response to precipitation events. The flashy response of the model watersheds is in part a consequence of low water storage in the modeled soil column.

We note that in the current implementation of GW, surface runoff is needlessly increased by the scaling factor 0.5 in the exponential term used to scale the precipitation rate [Eq.(7)]. Given the observations of Boone et al. (2004), Lohmann et al. (1998), and others regarding improved simulations obtained with models that have a low $Q_{s} / Q_{T}$, we suggest that this factor need be either eliminated (thereby effectively increased to
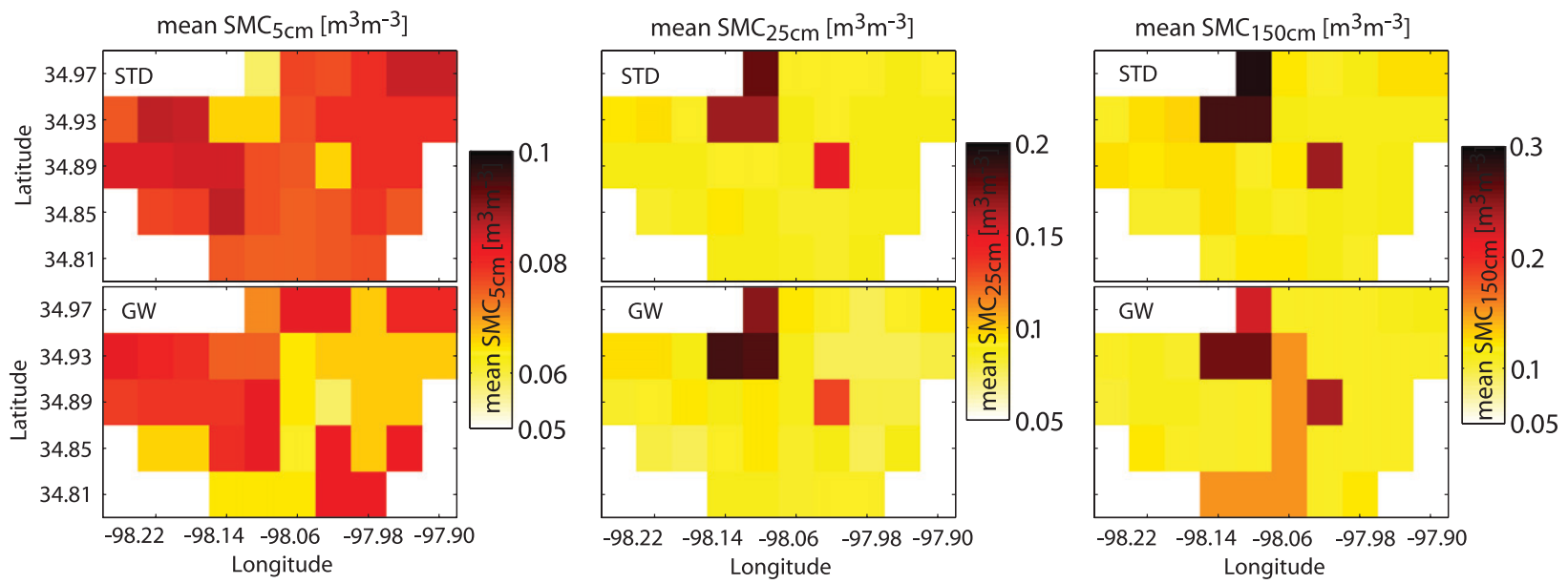

FIG. 14. Spatial distribution of ensemble-mean average SMC at depths of (a) 5, (b) 25, and (c) $150 \mathrm{~cm}$. SMC is shown for (top) STD and (bottom) GW. Note that the limits on the color bar legends are not the same between panels. SMC at $5 \mathrm{~cm}$ appears to be strongly related to soil-vegetation group. Models in general experience slow wettening with depth. 

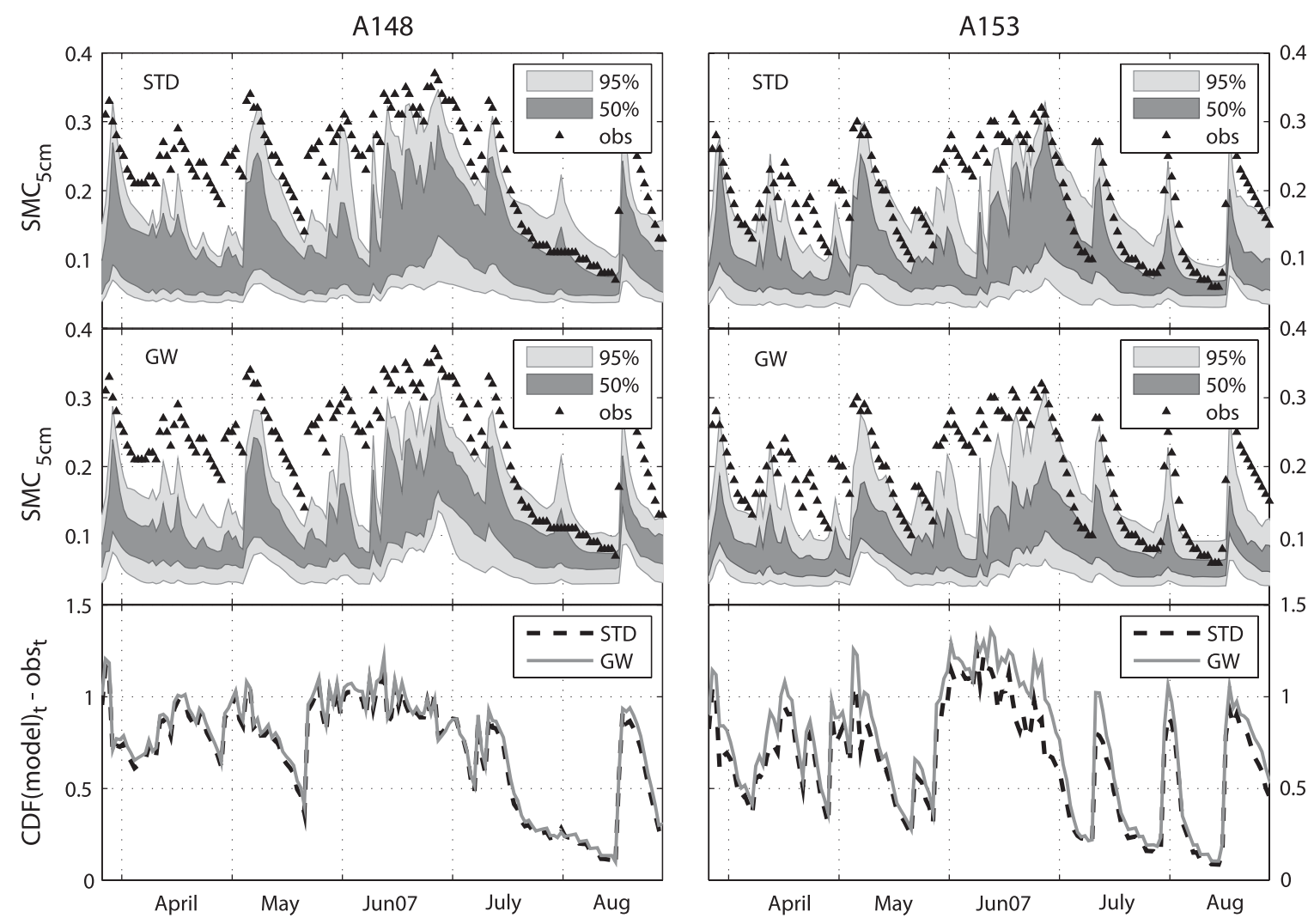

FIG. 15. Time series of observed and modeled 5-cm SMC at ARS sites A148 and A153 for the spring and summer of 2007. The 50\% and $95 \%$ confidence intervals of the subset of (top row) STD and (middle row) GW are plotted with daily-mean 5-cm SMC (triangles). Timevarying performance scores (lower is better) of both models are shown in the bottom row. STD slightly outperforms GW at A148 and outperforms GW at A153.

1.0) or increased to force a decrease in surface runoff. However, a simple decrease in surface runoff is not sufficient to create a constant supply of baseflow. Modifying the groundwater formulation used here such that it provides a time-delayed second reservoir for flow and such that it is able to generate a steady subsurface flow, even in regions where the water table is low, will likely improve the Noah LSM's capacity to simulate more physically realistic streamflow in the LWREW.

The current GW parameterization does provide a constant reservoir that is a potential source of runoff, but in its current implementation, GW does not function effectively when the water table is low because modeled surface and subsurface runoff decrease exponentially with water table depth [Eqs. (6) and (7)]. Given the current parameterization, when the water table falls below $10 \mathrm{~m}$ beneath the land surface, little subsurface runoff is produced (Fig. 18). The modeled equilibrium groundwater tables for the LWREW in the behavioral GW runs range from $1 \mathrm{~m}$ up to $80 \mathrm{~m}$ in some cells (Fig. 11 ), with most values being deeper than regional observations (10-30 m; USGS water data and D. Moriasi 2009, personal communication). While previous work using the same or similar implementations of Niu et al. (2007) have shown that the GW module performs realistically in simulating various aspects of the terrestrial water cycle (Niu and Yang 2003; Niu et al. 2007; Gulden et al. 2007; Lo et al. 2008: Rosero et al. 2009, 2010), it is necessary to point out that, in the other researchers' simulations, domain-average water tables have been shallow. GW seemed to degrade the simulation of near-surface fluxes and states in regions of transition zones were the water table is believed to be deep (Rosero et al. 2009, 2010).

One potential, domain-specific solution is to set the tunable parameter $f$ near zero such that there is only a very weak exponential dependency of runoff on depth to water [see Eqs. (6) and (7)]. We investigated physically plausible values of $f$ (Table 2). Niu and Yang (2003) provide a range from 1.5 to 5.2 of physically realistic values of $f$ reported in the literature using similar topography-based runoff schemes in somewhat similar modeling environments (Famiglietti et al. 1992; Stieglitz et al. 1997; Chen and Kumar 2001; Dai et al. 2003). The calibrated values adopted by Niu et al. $(2005,2007)$ are shown in Fig. 18. However, in such studies, the resolution of the grid cell was coarser, and the depth to the 
A148

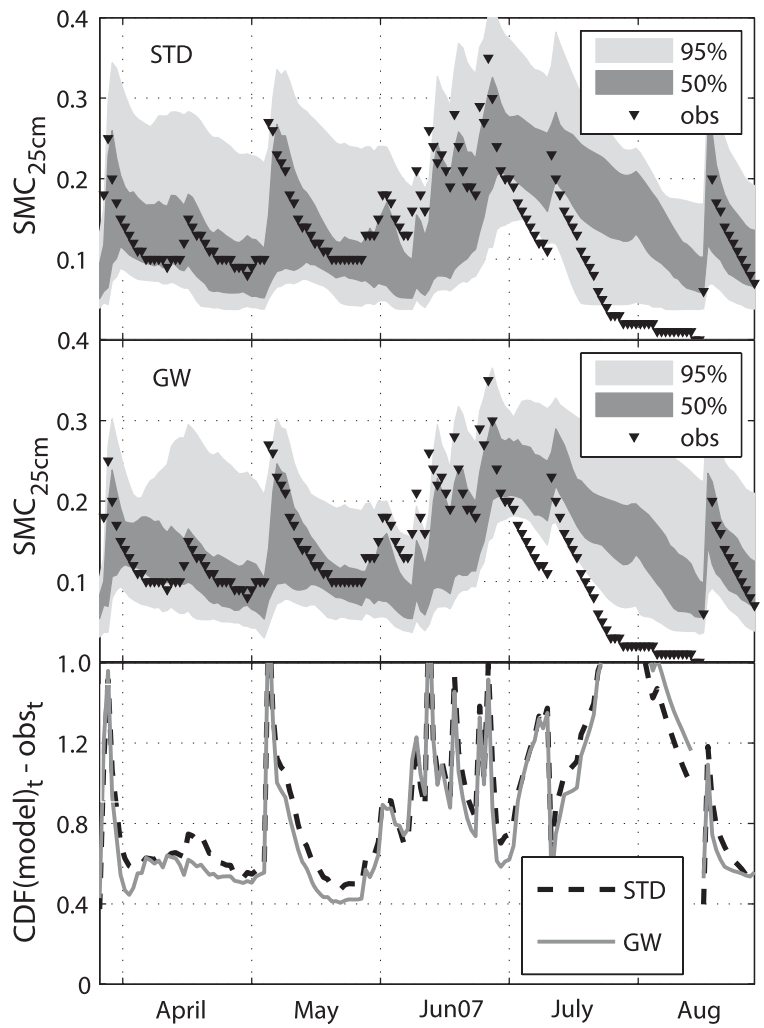

A153

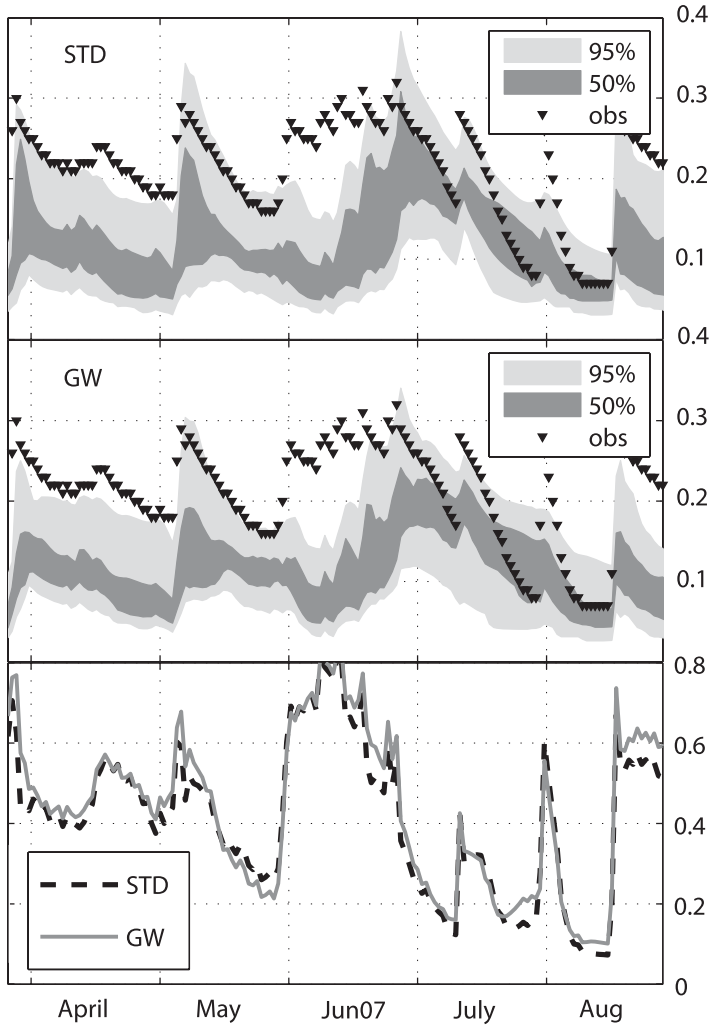

FIG. 16. As in Fig. 15, but for 25-cm SMC. GW outperforms STD at site A148; the models are approximately equally well suited to simulate site A153.

(parameterized) water table was relatively shallow, which made the exponential component of the subsurface runoff significantly greater [see Eq. (7)]. The ideal value of $f$ likely changes with gridcell size, soil properties, modeled equilibrium depth to water, and host model (Rosero et al. 2009). By comparing our runs with those of other researchers' results we clearly see that $f$ must be treated as a scale-dependent tunable parameter, not a physical quantity.

We also note that a potential explanation for the deeperthan-observed modeled water table is an overly robust parameterization of soil matric potential, which sucks water from the overly deep groundwater reservoir and contributes to significantly overestimated ET (Fig. 17).

Other potential explanations for the poor quality of simulated streamflow are that the soil hydrology representation of Noah is insufficiently complex and/or not realistic. This potential limitation is consistent with the poor-quality behavioral simulations of STD runoff, which appear to result from the model's low soil-water residence time. The increasing or constant $\mathrm{CV}$ with increasing mean soil moisture implies that the model does not have the capacity to retain or to buffer soil moisture. That is, model grid cells with high porosity likely have larger mean moisture because they occasionally are briefly saturated; however, all cells, including the cells that are wetter on average, dry quickly. For cells with higher porosity, this behavior increases the $\mathrm{CV}$ of soil moisture content. Such quick-to-wet, quick-to-dry behavior may be ameliorated by increasing the number of layers in the modeled soil column. However, such a change may be insufficient to fundamentally alter the statistics of the modeled soil moisture.

It is worth noting that Famiglietti et al. (2008), working in the same region, observed an overall increase in skewness with the scale of soil moisture measurements, which implies that positive skewness of the soil moisture distribution under dry surface conditions may be more pronounced at the larger end of a range of scales. This observation may help explain why our 4-km soil-moisture simulations have skewness values that are much larger than those of observations.

The runoff parameterizations within GW are related to topography but do not actually depend on the statistics of topography. In the development of the physically based parameterization of GW it was assumed that identification of parameters that, by derivation, are related to topography (fsatmx and rsbmax) has the potential to capture the heterogeneity of the land features and improve both 


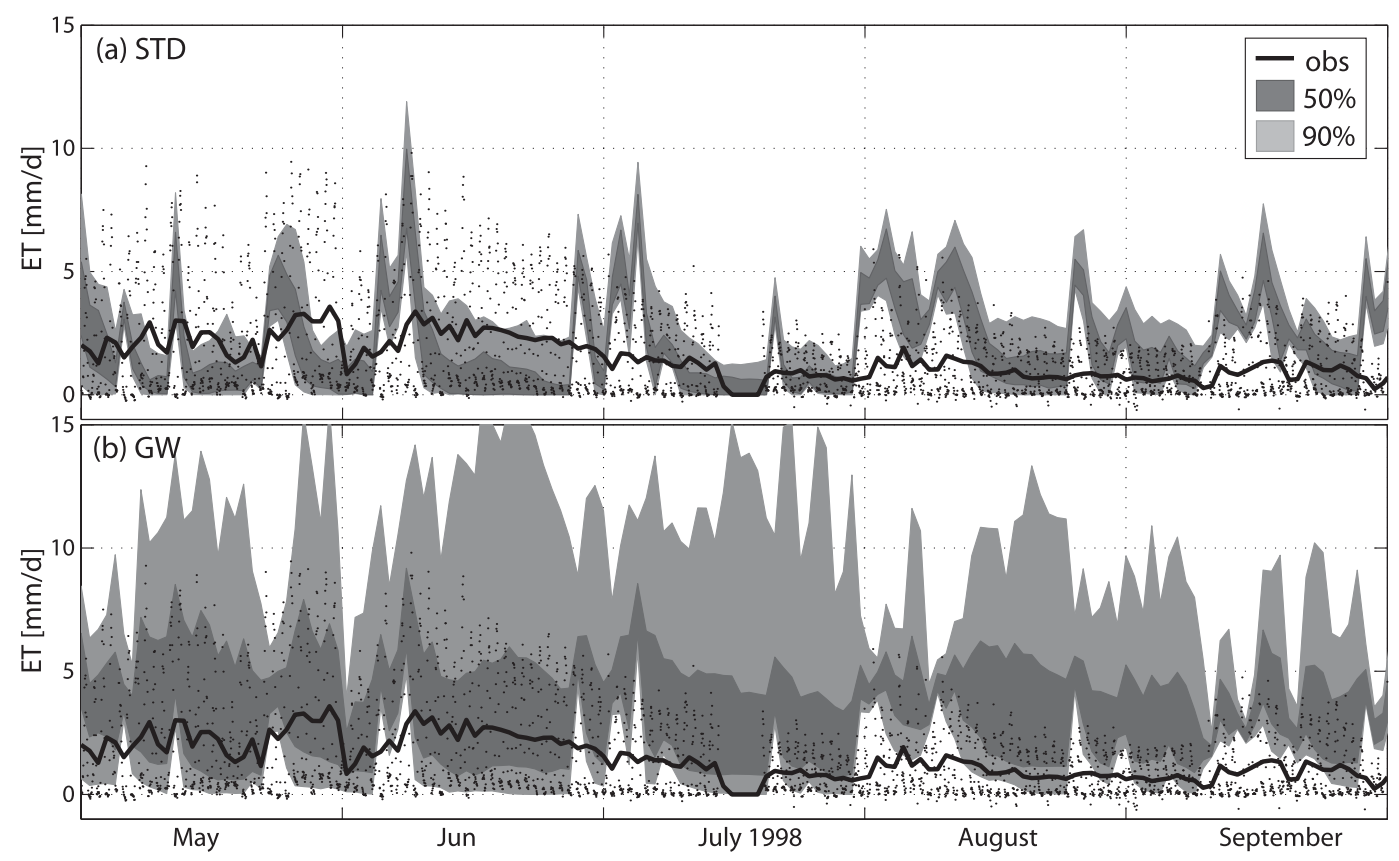

FIG. 17. Time series of simulated and observed ET at FLUXNET site Little Washita (Fig. 1a) for 1998. Black dots are hourly ET observations. Daily-mean observed values (black line) are significantly less variable and have a lower mean value than do the simulated daily-mean values (a) STD (b) GW. Both the $50 \%$ and $90 \%$ intervals of the behavioral subset of GW realizations overestimate ET.

simulated runoff and simulated soil moisture. Our sensitivity analysis showed that adjusting parameter rsbmx within GW to better reflect within-watershed variations of topography has little to no effect in improving both the statistics of soil moisture and the realism of the simulation of runoff. In the derivation in of the simplified model, Niu and Yang (2003) state "it is attractive to develop a topography-related runoff parameterization which does not require the topographic index data set. In the simplest case, the topographic characteristics may be parameterized as constants for all land points, and the saturated fraction and subsurface runoffs are only determined by the soil moisture represented by the water table depth." It is evident that the dependency of the gridcell topography is largely lost when using the simplification embedded within the maximum rate of subsurface runoff (rsbmx). Similarly, the conceptual maximum saturated fraction (fsatmx) becomes a tunable parameter. Hence, GW's simplifications for surface and subsurface runoff used here are disconnected from the actual physics of topographic influence on groundwater discharge. It is therefore not surprising that, without extensive calibration, they do not yield significant improvement in the physical realism of model simulations.

In the LWREW, a combination approach may be warranted. GW is a modified saturation-excess runoff scheme, which is valid in humid regions, zones with large infiltration capacity, and well-distributed precipitation. STD uses an infiltration-excess scheme, which is better suited to dry regions with sparse, localized rain or in humid areas where soils are impermeable.

To accurately predict streamflow or other hydrologic fluxes and states, choosing the appropriate model structure (and model parameters) is a crucial step in hydrologic modeling. The same can be said about understanding the dominant physical controls on the response of a watershed (Clark et al. 2008). In land surface modeling, often a bottom-up approach is followed (as is done here). LSM are complex structures that generally require detailed information of the physical characteristics of the modeled watersheds and are often potentially overparameterized. As pointed out by Jakeman and Hornberger (1993), model overparameterization is particularly acute when simulating streamflow. Instead, and in the context of hypothesis testing, a top-down approach to model development is advisable (e.g., Farmer et al. 2003; Schultz and Beven 2003; Sivapalan et al. 2003; Bai et al. 2009). The aim should be to identify a model structure with the minimum level of complexity that is capable of reproducing the observed watershed response for the "right reasons" (Kirchner 2006). The gap between the simplified hydrological model components implemented in atmospheric models and the state-of-the-art integrated hydrological models (Overgaard et al. 2006) can only be bridged with approaches that systematically increase the complexity of 

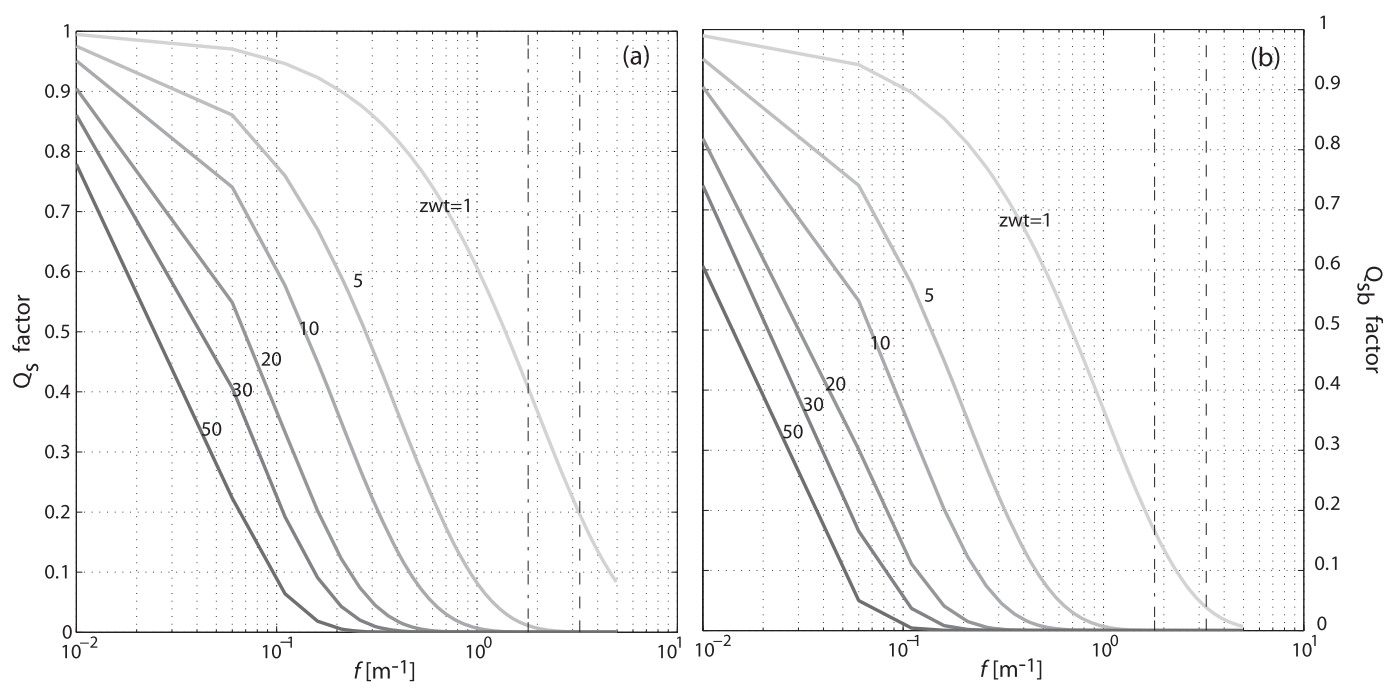

FIG. 18. Sensitivity of GW's (a) surface and (b) subsurface runoff to depth to water table $\left(z_{\mathrm{wt}}\right)$ and $e$-folding depth $f$ (exponential decay of saturated hydraulic conductivity). Dashed lines are values of calibrated parameters used by Niu et al. $(2005 ; 2007)$.

the subsurface hydrologic parameterization in a framework that acknowledges explicitly the inherent uncertainty of the problem (Clark et al. 2008).

Acknowledgments. The first author was supported by the Graduate Fellowship of the Hydrology Training Program of the OHD/NWS. The project was also funded by the NOAA Grant NA07OAR4310216, the NOAACPPA Proposal GC08-521, NSF, and the Jackson School of Geosciences. Bailing Li, at NASA/GSFC, provided us with $1 \mathrm{~km}$-LIS land-cover, monthly vegetation fraction and albedo climatology data. The NEXRAD stage IV was prepared by Seungbum Hong at UT Austin. We acknowledge the USGS, ARS micronet and AmeriFlux for the validation datasets. We thank D. J. Gochis at NCAR and K. Mitchell at NCEP for their insight. We benefited from the computational resources at the Texas Advanced Computing Center (TACC).

\section{REFERENCES}

Allen, P. B., and J. W. Naney, 1991: Hydrology of the Little Washita River Watershed, Oklahoma: Data and analyses. U.S. Department of Agriculture, Agricultural Research Service, ARS-90, $74 \mathrm{pp}$.

Bai, Y., T. Wagener, and P. Reed, 2009: A top-down framework for watershed model evaluation and selection under uncertainty. Environ. Model. Software, 24, 901-916, doi:10.1016/j.envsoft. 2008.12.012.

Bastidas, L. A., T. S. Hogue, S. Sorooshian, H. V. Gupta, and W. J. Shuttleworth, 2006: Parameter sensitivity analysis for different complexity land surface models using multicriteria methods. J. Geophys. Res., 111, D20101, doi:10.1029/ 2005JD006377.
Bates, B. C., Z. W. Kundzewicz, S. Wu, and J. P. Palutikof, 2008: Climate change and water. Intergovernmental Panel on Climate Change Tech. Paper, 210 pp.

Beven, K. J., 1989: Changing ideas of hydrology: The case of physically based models. J. Hydrol., 105, 157-172.

_ 2001: How far can we go in distributed hydrological modelling? Hydrol. Earth Syst. Sci., 5, 1-12.

_ 2002: Towards an alternative blueprint for a physically based digitally simulated hydrologic response modelling system. Hydrol. Processes, 16, 189-206.

_ and A. Binley, 1992: The future of distributed models: Model calibration and uncertainty prediction. Hydrol. Processes, 6, 279-298.

Boone, A., and Coauthors, 2004: The Rhône-Aggregation Land Surface Scheme intercomparison project: An overview. J. Climate, 17, 187-208

Box, G. E. P., and D. R. Cox, 1964: An analysis of transformations. J. Roy. Stat. Soc., 26, 211-252.

Chen, F., and J. Dudhia, 2001: Coupling an advanced land surfacehydrology model with the Penn State-NCAR MM5 modeling system. Part I: Model implementation and sensitivity. Mon. Wea. Rev., 129, 569-586.

_ by four schemes and comparison with FIFE observations J. Geophys. Res., 101 (D3), 7251-7268.

Chen, J., and P. Kumar, 2001: Topographic influence on the seasonal and inter-annual variation of water and energy balance of basins in North America. J. Climate, 14, 1989-2014.

Chen, T. H., and Coauthors, 1997: Cabauw experimental results from the Project for Intercomparison of Land-Surface Parameterization Schemes. J. Climate, 10, 1194-1215.

Clapp, R. B., and G. M. Hornberger, 1978: Empirical equations for some soil hydraulic properties. Water Resour. Res., 14, 601-604.

Clark, M. P., A. G. Slater, D. E. Rupp, R. A. Woods, J. A. Vrugt, H. V. Gupta, T. Wagener, and L. E. Hay, 2008: Framework for Understanding Structural Errors (FUSE): A modular framework to diagnose differences between hydrological models. Water Resour. Res., 44, W00B02, doi:10.1029/2007WR006735. 
Cosgrove, B. A., and Coauthors, 2003: Real-time and retrospective forcing in the North American Land Data Assimilation System (NLDAS) project. J. Geophys. Res., 108, 8842, doi:10.1029/ 2002JD003118.

Dai, Y., and Coauthors, 2003: The Common Land Model. Bull. Amer. Meteor. Soc., 84, 1013-1023.

Dirmeyer, P. A., 2006: The hydrologic feedback pathway for landclimate coupling. J. Hydrometeor., 7, 857-867.

Ducharne, A., R. D. Koster, M. J. Suarez, M. Stieglitz, and P. Kumar, 2000: A catchment-based approach to modeling land surface processes in a general circulation model 2. Parameter estimation and model demonstration. J. Geophys. Res., 105 (D20), 24 823-24 838.

Ek, M. B., K. E. Mitchell, Y. Lin, E. Rogers, P. Grunmann, V. Koren, G. Gayno, and J. D. Tarpley, 2003: Implementation of Noah land surface model advances in the National Centers for Environmental Prediction operational mesoscale Eta model. J. Geophys. Res., 108, 8851, doi:10.1029/ 2002JD003296.

Famiglietti, J. S., E. F. Wood, M. Sivapalan, and D. J. Thongs, 1992: A catchment scale water balance model for FIFE. J. Geophys. Res., 97, 18 997-19 007.

—, D. Ryu, A. A. Berg, M. Rodell, and T. J. Jackson, 2008: Field observations of soil moisture variability across scales. Water Resour. Res., 44, W01423, doi:10.1029/2006WR005804.

Fan, Y., G. Miguez-Macho, C. P. Weaver, R. Walko, and A. Robock, 2007: Incorporating water table dynamics in climate modeling: 1. Water table observations and the equilibrium water table J. Geophys. Res., 112, D10125, doi:10.1029/2006JD008111.

Farmer, D., M. Sivapalan, and C. Jothityangkoon, 2003: Climate, soil, and vegetation controls upon the variability of water balance in temperate and semiarid landscapes: Downward approach to water balance analysis. Water Resour. Res., 39, 1035, doi:10.1029/2001WR000328.

Gulden, L. E., E. Rosero, Z.-L. Yang, M. Rodell, C. S. Jackson, G.-Y. Niu, P. J.-F. Yeh, and J. Famiglietti, 2007: Improving land-surface model hydrology: Is an explicit aquifer model better than a deeper soil profile? Geophys. Res. Lett., 34, L09402, doi:10.1029/2007GL029804.

,,,--- T. Wagener, and G.-Y. Niu, 2008: Model performance, model robustness, and model fitness scores: A new method for identifying good land-surface models. Geophys. Res. Lett., 35, L11404, doi:10.1029/2008GL033721.

Gutowski, W. J., Jr., C. J. Vörösmarty, M. Person, Z. Ötles, B. Fekete, and J. York, 2002: A Coupled Land-Atmosphere Simulation Program (CLASP): Calibration and validation. J. Geophys. Res., 107, 4283, doi:10.1029/2001JD000392.

Hansen, M. C., R. S. DeFries, J. R. G. Townshend, and R. Sohlberg, 2000: Global land cover classification at $1 \mathrm{~km}$ spatial resolution using a classification tree approach. Int. J. Remote Sens., 21 (6-7), 1389-1414.

Hogue, T. S., L. A. Bastidas, H. V. Gupta, and S. Sorooshian, 2006: Evaluating model performance and parameter behavior for varying levels of land surface model complexity. Water Resour. Res., 42, W08430, doi:10.1029/2005WR004440.

Hornberger, G. M., and R. C. Spear, 1981: An approach to the preliminary analysis of environmental systems. J. Environ. Manage., 12, 7-18.

Jakeman, A. J., and G. M. Hornberger, 1993: How much complexity is warranted in a rainfall-runoff model? Water Resour. Res., 29, 2637-2649.

Kirchner, J. W., 2006: Getting the right answers for the right reasons: Linking measurements, analyses, and models to advance the science of hydrology. Water Resour. Res., 42, W03S04, doi:10.1029/2005WR004362.

Kollet, S. J., and R. M. Maxwell, 2008: Capturing the influence of groundwater dynamics on land surface processes using an integrated, distributed watershed model. Water Resour. Res., 44, W02402, doi:10.1029/2007WR006004.

Konikow, L. F., and J. D. Bredehoeft, 1992: Groundwater models cannot be validated. Adv. Water Resour., 15, 13-24.

Koster, R. D., and P. C. D. Milly, 1997: The interplay between transpiration and runoff formulations in land surface schemes used with atmospheric models. J. Climate, 10, 1578-1591.

_- M. J. Suarez, A. Ducharne, M. Stieglitz, and P. Kumar, 2000: A catchment-based approach to modeling land surface processes in a general circulation model 1. Model structure. J. Geophys. Res., 105 (D20), 24 809-24 822.

Li, H., A. Robock, and M. Wild, 2007: Evaluation of Intergovernmental Panel on Climate Change Fourth Assessment soil moisture simulations for the second half of the twentieth century. J. Geophys. Res., 112, D06106, doi:10.1029/ 2006JD007455.

Liang, X., E. F. Wood, and D. P. Lettenmaier, 1996: Surface soil moisture parameterization of the VIC-2L model: Evaluation and modification. Global Planet. Change, 13, 195-206.

- and Coauthors, 1998: The Project for Intercomparison of Land-surface Parameterization Schemes (PILPS) phase 2(c) Red-Arkansas River basin experiment: 2. Spatial and temporal analysis of energy fluxes. Global Planet. Change, 19, 137-159.

_- Z. Xie, and M. Huang, 2003: A new parameterization for surface and groundwater interactions and its impact on water budgets with the variable infiltration capacity (VIC) land surface model. J. Geophys. Res., 108, 8613, doi:10.1029/ 2002JD003090.

Lo, M. H., P. J. F. Yeh, and J. S. Famiglietti, 2008: Constraining water table depth simulations in a land surface model using estimated baseflow. Adv. Water Resour., 31, 1552-1564.

Lohmann, D., and Coauthors, 1998: The Project for Intercomparison of Land-surface Parameterization Schemes (PILPS) phase 2(c) Red-Arkansas River basin experiment: 3. Spatial and temporal analysis of water fluxes. Global Planet. Change, 19, 161-179.

Maxwell, R. M., and N. L. Miller, 2005: Development of a coupled land surface and groundwater model. J. Hydrometeor., 6, 233-247.

McKay, M., R. Beckman, and W. Conover, 1979: A comparison of three methods for selecting values of input variables in the analysis of output from a computer code. Technometrics, $\mathbf{2 1}$, 239-245

Meyers, T. P., 2001: A comparison of summertime water and $\mathrm{CO}_{2}$ fluxes over rangeland for well watered and drought conditions. Agric. For. Meteor., 106, 205-214.

Mitchell, K. E., and Coauthors, 2004: The multi-institution North American Land Data Assimilation System (NLDAS): Utilizing multiple GCIP products and partners in a continental distributed hydrological modeling system. J. Geophys. Res., 109, D07S90, doi:10.1029/2003JD003823.

Nasonova, O. N., Y. M. Gusev, and Y. E. Kovalev, 2009: Investigating the ability of a land surface model to simulate streamflow with the accuracy of hydrological models: A case study using MOPEX materials. J. Hydrometeor., 10, 1128-1150.

Nijseen, B., and L. A. Bastidas, 2005: Land-atmosphere models for water and energy cycle studies. Encyclopedia of Hydrological Sciences, M. G. Anderson, Ed., Vol. 5, John Wiley, 3089-3102. 
Niu, G.-Y., and Z.-L. Yang, 2003: The versatile integrator of surface and atmosphere processes (VISA). Part II: Evaluation of three topography-based runoff schemes. Global Planet. Change, 38, 191-208.

- — , R. E. Dickinson, and L. E. Gulden, 2005: A simple TOPMODEL-based runoff parameterization (SIMTOP) for use in GCMs. J. Geophys. Res., 110, D21106, doi:10.1029/ 2005JD006111.

,,,---- , and H. Su, 2007: Development of a simple groundwater model for use in climate models and evaluation with Gravity Recovery and Climate Experiment data. J. Geophys. Res., 112, D07103, doi:10.1029/2006JD007522.

Oki, T., T. Nishimura, and P. Dirmeyer, 1999: Assessment of land surface models by runoff in major river basins of the globe using Total Runoff Integrating Pathways (TRIP). J. Meteor. Soc. Japan, 77, 235-255.

Overgaard, J., D. Rosbjerg, and M. B. Butts, 2006: Land-surface modelling in hydrological perspective-A review. Biogeosciences, 3, 229-241.

Pitman, A. J., 2003: Review: The evolution of, and revolution in, land surface schemes designed for climate models. Int. J. Climatol., 23, 479-510, doi:10.1002/joc.893.

— , and Coauthors, 1999: Key results and implications from Phase 1(c) of the Project for Intercomparison of Land-surface Parameterization Schemes. Climate Dyn., 15, 673-684.

Ratto, M., P. C. Young, R. Romanowicz, F. Pappenberger, A. Saltelli, and A. Pagano, 2007: Uncertainty, sensitivity analysis and the role of data based mechanistic modeling in hydrology. Hydrol. Earth Syst. Sci., 11, 1249-1266.

Refsgaard, J. C., 1997: Parameterization, calibration and validation of distributed hydrological models. J. Hydrol., 198, 69-97.

— , and H. J. Henriksen, 2004: Modelling guidelines terminology and guiding principles. Adv. Water Resour., 27, 71-82.

Reichle, R. H., and R. D. Koster, 2005: Global assimilation of satellite surface soil moisture retrievals into the NASA Catchment land surface model. Geophys. Res. Lett., 32, L02404, doi:10.1029/2004GL021700.

Rosero, E., Z.-L. Yang, L. E. Gulden, G.-Y. Niu, and D. J. Gochis, 2009: Evaluating enhanced hydrological representations in Noah LSM over transition zones: Implications for model development. J. Hydrometeor., 10, 600-622.

- — - - T. Wagener, L. E. Gulden, S. Yatheendradas, and G.-Y. Niu, 2010: Quantifying parameter sensitivity, interaction and transferability in hydrologically enhanced versions of Noah-LSM over transition zones. J. Geophys. Res., 115, D03106, doi:10.1029/2009JD012035.

Saltelli, A., 2002: Making best use of model evaluations to compute sensitivity indices. Comput. Phys. Commun., 145, 280-297.

_- A. Tarantola, F. Campolongo, and M. Ratto, 2004: Sensitivity Analysis in Practice: A Guide to Assessing Scientific Models. John Wiley and Sons, $232 \mathrm{pp}$.

Schaake, J. C., V. I. Koren, Q.-Y. Duan, K. Mitchell, and F. Chen, 1996: Simple water balance model for estimating runoff at different spatial and temporal scales. J. Geophys. Res., 101 (D3), 7461-7475.

Schultz, K., and K. Beven, 2003: Data-supported robust parameterizations in land surface-atmosphere flux predictions: Toward a top-down approach. Hydrol. Processes, 17, 2259-2277.

Sivapalan, M., K. Beven, and E. F. Wood, 1987: On hydrologic similarity: 2. A scaled model of storm runoff production. Water Resour. Res., 23, 2266-2278.
— G. Blöschl, L. Zhang, and R. Vertessy, 2003: Downward approach to hydrological prediction. Hydrol. Processes, 17, 2101-2111, doi:10.1002/hyp.1425.

Smakhtin, U., 2001: Low flow hydrology: A review. J. Hydrol., 240, 147-186.

Sobol', I. M., 1993: Sensitivity analysis for nonlinear mathematical models. Math. Models Comput. Exp., 1, 407-414.

__ 2001: Global sensitivity indices for nonlinear mathematical models and their Monte Carlo estimates. Math. Comput. Simul., 55, 271-280, doi:10.1016/S0378-4754(00)00270-6.

Soil Survey Staff, cited 2009: U.S. General Soil Map (STATSGO2) for Oklahoma. Natural Resources Conservation Service, United States Department of Agriculture. [Available online at http://soildatamart.nrcs.usda.gov.]

Sorooshian, S., and J. A. Dracup, 1980: Stochastic parameter estimation procedures for hydrologic rainfall-runoff models: Correlated and heteroscedastic error cases. Water Resour. Res., 16, 430-442.

Stieglitz, M., D. Rind, J. Famiglietti, and C. Rosenzweig, 1997: An efficient approach to modeling the topographic control of surface hydrology for regional and global modeling. J. Climate, 10, 118-137.

Stöckli, R., P. L. Vidale, A. Boone, and C. Schär, 2007: Impact of scale and aggregation on the terrestrial water exchange: Integrating land surface models and Rhône catchment observations. J. Hydrometeor., 8, 1002-1015.

— , and Coauthors, 2008: Use of FLUXNET in the Community Land Model development. J. Geophys. Res., 113, G01025, doi:10.1029/2007JG000562.

van Werkhoven, K., T. Wagener, P. Reed, and Y. Tang, 2008: Characterization of watershed model behavior across a hydroclimatic gradient. Water Resour. Res., 44, W01429, doi:10.1029/2007WR006271.

Viterbo, P., 2002: A review of parametrization schemes for land surface processes. Meteorological Training Course Lecture Series, ECMWF, Shinfield Park, Reading, United Kingdom, 1-49.

Vogel, R. M., and N. M. Fennessey, 1994: Flow duration curves. I. A new interpretation and confidence intervals. J. Water Resour. Plann. Manage., 120, 485-504.

Wagener, T., M. Sivapalan, P. Troch, and R. Woods, 2007: Catchment classification and hydrologic similarity. Geogr. Compass, 1, 901-931, doi:10.1111/j.1749-8198.2007.00039.x.

Wetzel, P., and Coauthors, 1996: Modeling vadose zone liquid water fluxes: Infiltration, runoff, drainage, interflow. Global Planet. Change, 13, 57-71.

Wood, E. F., D. P. Lettenmaier, and V. G. Zartarian, 1992: A landsurface hydrology parameterization with subgrid variability for general circulation models. J. Geophys. Res., 97 (D3), $2717-2728$.

— Land-surface Parameterization Schemes (PILPS) phase 2(c) Red-Arkansas River basin experiment: 1. Experiment description and summary intercomparisons. Global Planet. Change, 19, 115-135.

Yeh, P. J.-F., and E. A. B. Eltahir, 2005: Representation of water table dynamics in a land-surface scheme. Part I: Model development. J. Climate, 18, 1861-1880.

Yilmaz, K. K., H. V. Gupta, and T. Wagener, 2008: A processbased diagnostic approach to model evaluation: Application to the NWS distributed hydrologic model. Water Resour. Res. 44, W09417, doi:10.1029/2007WR006716. 
Copyright of Journal of Hydrometeorology is the property of American Meteorological Society and its content may not be copied or emailed to multiple sites or posted to a listserv without the copyright holder's express written permission. However, users may print, download, or email articles for individual use. 